\title{
1 MCL-1 inhibition by selective BH3 mimetics disrupts 2 mitochondrial dynamics in iPSC-derived cardiomyocytes
}

3

4

5

6

${ }^{1 \# M e g a n ~ L . ~ R a s m u s s e n, ~}{ }^{1 \#}$ Nilay Taneja, ${ }^{1}$ Abigail C. Neininger, ${ }^{2}$ Lili Wang, ${ }^{1}$ Linzheng Shi, ${ }^{2}$ Bjorn C. Knollmann, ${ }^{1,3,5}$ Dylan T. Burnette and ${ }^{1,3,4,5,6,{ }^{*} \text { Vivian Gama }}$

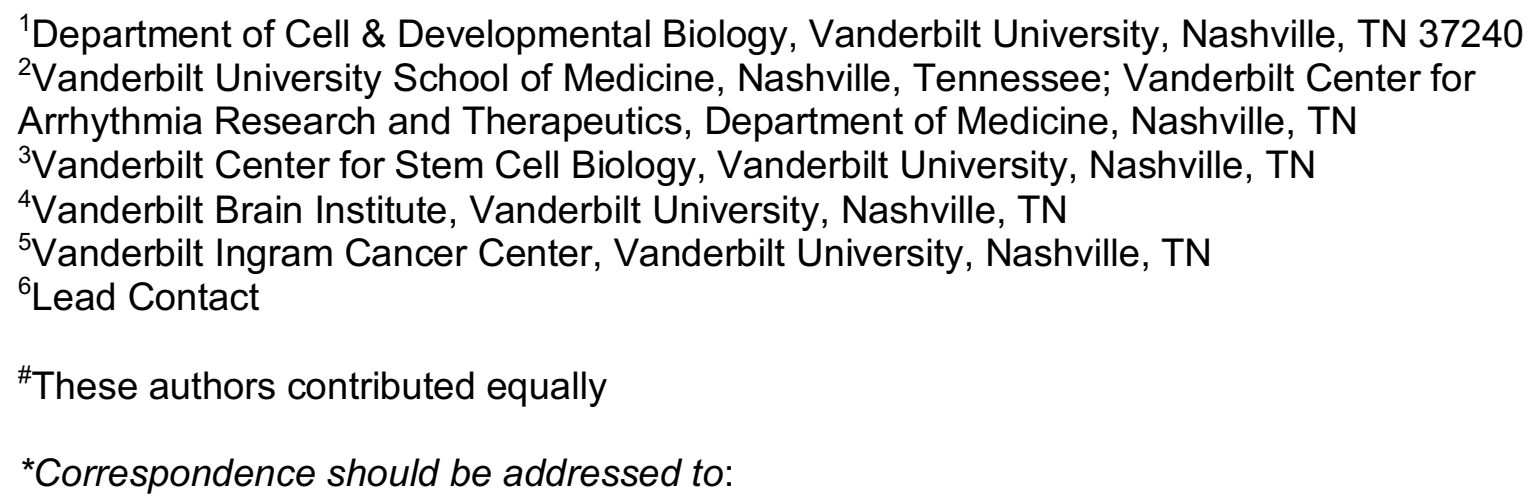

Running Title: MCL-1 inhibition disrupts mitochondrial dynamics in hPSC-CMs 


\section{Summary}

MCL-1 is a well characterized inhibitor of cell death that has also been shown to be a

41 regulator of mitochondrial dynamics in human pluripotent stem cells (hPSCs). We used

42 cardiomyocytes derived from hPSCs (hPSC-CMs) to uncover whether MCL-1 is crucial for cardiac

43 function and survival. Inhibition of MCL-1 by $\mathrm{BH} 3$ mimetics, resulted in the disruption of

44 mitochondrial morphology and dynamics as well as disorganization of the actin cytoskeleton.

45 Interfering with MCL-1 function affects the homeostatic proximity of DRP-1 and MCL-1 at the outer

46 mitochondrial membrane, resulting in decreased functionality of hPSC-CMs. BH3 mimetics

47 targeting MCL-1 are promising anti-tumor therapeutics. Cardiomyocytes display abnormal

48 functional cardiac performance even after caspase inhibition, supporting a non-apoptotic activity

49 of MCL-1 in hPSC-CMs. Progression towards using BCL-2 family inhibitors, especially targeting

50 MCL-1, depends on understanding not only its canonical function in preventing apoptosis, but

51 also in the maintenance of mitochondrial dynamics and function.

52

53

54

55

56

57

58

59

60

61

62 Keywords: Apoptosis, MCL-1, pluripotent stem cells, cardiomyocytes, mitochondria, DRP-1,

63 OPA1, BH3, cancer, mitochondrial dynamics 


\section{Introduction}

Myeloid cell leukemia-1 (MCL-1) was originally identified as an early-induced gene in human myeloid leukemia cell differentiation (Kozopas et al., 1993; Reynolds et al., 1996; Yang et al., 1996). MCL-1 is structurally similar to other anti-apoptotic BCL-2 (B cell lymphoma-2) family proteins (i.e. BCL-2, BCL-XL (B cell lymphoma extra-large)) (Chipuk et al., 2010). However, its larger, unstructured $\mathrm{N}$-terminal domain and shorter half-life likely indicated that MCL-1 was not completely functionally redundant with other anti-apoptotic proteins (Perciavalle and Opferman, 2013). Supporting this idea, MCL-1 has been shown to be essential for embryonic development and for the survival of various cell types, including cardiomyocytes, neurons, and hematopoietic stem cells (Rinkenberger et al., 2000; Thomas et al., 2010; Wang et al., 2013; Opferman, 2016).

MCL-1 is one of the most amplified genes in human cancers and is frequently associated with resistance to chemotherapy (Beroukhim et al., 2010; Perciavalle and Opferman, 2013). Earlier work demonstrated that MCL-1 genetic deletion is peri-implantation lethal in embryogenesis, not due to defects in apoptosis, but rather due to a combination of an embryonic developmental delay and an implantation defect (Rinkenberger et al., 2000). However, the nonapoptotic mechanism by which MCL-1 functions in normal and cancerous cells is still unclear. We previously reported that $\mathrm{MCL}-1$ regulates mitochondrial dynamics in human pluripotent stem cells (hPSCs, which refers to both human embryonic stem cells (hESCs) and induced pluripotent stem cells (hiPSCS)) (Rasmussen et al., 2018). We found that MCL-1 maintains mitochondrial network homeostasis in hPSCs through interactions with Dynamin related protein-1 (DRP-1) and Optic atrophy type 1 (OPA1). In this study, we investigated whether this non-apoptotic role of MCL-1 remains as stem cells differentiate, using cardiomyocytes derived from human induced pluripotent stem cells (hiPSC-CMs).

Mitochondrial fusion promotes elongation of the mitochondrial network, which is key for mitochondrial DNA (mtDNA) homogenization and efficient assembly of the electron transport chain (ETC) (Westermann, 2010; Friedman and Nunnari, 2014). Loss of mitochondrial fusion has 
91 been implicated as a mechanism for the onset of dilated cardiomyopathy (Dorn, 2013).

92 Mitochondria also regulate cardiomyocyte differentiation and embryonic cardiac development

93 (Kasahara et al., 2013; Kasahara and Scorrano, 2014; Cho et al., 2014). However, there is limited

94 information about the mechanisms used by cardiomyocytes to minimize the risks for apoptosis,

95 especially in cells derived from highly sensitive stem cells (Imahashi et al., 2004; Murriel et al.,

96 2004; Gama and Deshmukh, 2012; Dumitru et al., 2012; Walensky, 2012).

97 Ultrastructural changes have long been observed in response to alterations in oxidative 98 metabolism (Hackenbrock, 1966; Khacho et al., 2016). It has become increasingly clear that 99 individual mitochondrial shape changes can also have dramatic effects on cellular metabolism.

100 Mitochondrial morphology and cristae structure are influenced by fission and fusion events;

101 subsequently, ETC complexes that reside on the inner mitochondrial membrane are disrupted 102 upon aberrant fission (Chan, 2007). Several human diseases, such as MELAS (Muscle atrophy,

103 Encephalopathy, Lactic Acidosis, Stroke-like episodes) and Dominant Optic Atrophy (DOA), are 104 associated with mutations in the mitochondrial dynamics and mitochondrial metabolism machineries (Chan, 2007; Hsu et al., 2016). Likewise, many neurological conditions, including 106 Parkinson's disease, Huntington's disease, and Charcot-Marie Tooth Type 2 syndrome, can 107 originate from alterations in mitochondrial dynamics and metabolic regulation (Itoh et al., 2013; 108 Burté et al., 2015). Besides neurological conditions, several studies in the heart suggest that 109 alterations in mitochondrial dynamics causes abnormal mitochondrial quality control, resulting in 110 the buildup of defective mitochondria and reactive oxygen species (ROS) (Galloway and Yoon, 111 2015; Song et al., 2017). Interestingly, it has been shown that modulating the production of ROS 112 can favor or prevent differentiation into cardiomyocytes (Buggisch et al., 2007; Murray et al., 113 2014). Thus, specific metabolic profiles controlled by mitochondrial dynamics are likely critical for 114 hiPSC-CMs, since they can influence cell cycle, biomass, metabolite levels, and redox state 115 (Zhang et al., 2012). 
It is not completely understood how dynamic changes in metabolism affect cardiomyocyte

117 function. Deletion of MCL-1 in murine heart muscle resulted in lethal cardiomyopathy, reduction

118 of mitochondrial DNA (mtDNA), and mitochondrial dysfunction (Wang et al., 2013). Inhibiting

119 apoptosis via concurrent BAK/BAX knockout allowed for the survival of the mice; conversely, the

120 mitochondrial ultrastructure abnormalities and respiratory deficiencies were not rescued. These

121 results indicate that MCL-1 also has a crucial function in maintaining cell viability and metabolic

122 profile in cardiomyocytes. Despite these efforts, the non-apoptotic mechanism by which MCL-1

123 specifically functions in cardiomyocytes is still unknown. Furthermore, a role for MCL-1 in the

124 regulation of mitochondrial dynamics in cardiac cells has not yet been defined. Here we describe

125 findings that MCL-1 is essential for the survival of hiPSC-CMs by maintaining mitochondrial 126 morphology and function.

Results and Discussion

MCL-1 inhibition causes severe defects in hiPSC-CM mitochondrial network.

Recently published small molecule inhibitors of MCL-1 have been anticipated as potent antitumor agents against MCL-1-dependent cancers with limited cardiotoxicity in mouse models (Cohen et al., 2012; Kotschy et al., 2016; Letai, 2016). Thus, we chose to use hiPSC-CMs (Figure 1A) to examine the effects of MCL-1 inhibition on mitochondrial morphology, using the small molecule inhibitor $\$ 63845$ (Kotschy et al., 2016), combined with structured illumination microscopy (SIM) to observe mitochondria at high-resolution (Figure 1B). Cardiomyocytes were

137 images after 4 days of treatment with vehicle (DMSO) or MCL-1 inhibitor (MCL-1i/S63845) and 138 the caspase inhibitor Q-VD-OPh (QVD) (Figure 1B). We found that MCL-1 inhibition had 139 significant effects on iPSC-CM mitochondrial morphology. Mitochondrial networks in S63845140 treated cells were severely disrupted, with individual mitochondria becoming more fragmented 141 and globular, as opposed to elongated and interconnected networks in control cells (Figure 1C). 
142 In a previous report, MCL-1 inhibition using RNAi also resulted in mitochondria morphology

143 defects including severe cristae disruption and remarkable vacuolation in the mitochondrial matrix

144 (Guo et al., 2018). Recent reports have determined that MCL-1 functions not only as an apoptosis

145 regulator but also as a modulator of mitochondrial morphology and dynamics (Perciavalle et al.,

146 2012; Morciano et al., 2016; Rasmussen et al., 2018). Thus, we hypothesized that inhibiting MCL-

1471 with $\mathrm{BH} 3$ mimetics would affect the functionality of human cardiomyocytes, due to the disruption

148 of crucial MCL-1 interactions with the mitochondrial dynamics machinery, which ultimately will

149 lead to cell death.

150

MCL-1 inhibition affects contractility of iPSC-CMs and myofibril assembly in a caspaseindependent manner.

MCL-1 inhibition by $\mathrm{S} 63845$ was shown to have minimal effects on murine ejection fraction

154 (Kotschy et al., 2016) and on overall cardiac function in human cardiomyocytes (Guo et al., 2018).

These results are intriguing considering previous studies reporting that MCL-1 deletion from using phase-contrast live-cell imaging. We observed lower numbers of beating cells when treated with 1-2 $\mu \mathrm{M} \mathrm{MCL-1i} \mathrm{(S63845),} \mathrm{and} \mathrm{the} \mathrm{cells} \mathrm{that} \mathrm{were} \mathrm{beating} \mathrm{appeared} \mathrm{to} \mathrm{beat} \mathrm{more} \mathrm{slowly}$ (Figure S1A-C). To assess these defects more rigorously, we plated cells on a multi-electrode array (MEA) plate and examined cardiac function using the Axion Biosystems analyzer (Clements and Thomas, 2014) (Figure 2A). We observed that MCL-1 inhibition caused severe defects in

164 cardiomyocyte functionality after just 18 hours of the first treatment (Figure 2B-D). In particular, 165 beat period irregularity was significantly increased (Figure 2B), while spike amplitude and spike 166 slope means were decreased (Figure 2C-D). The differences between beat period mean and 167 conduction velocity mean at this time point were not significant (Figure S1D-E); however, at just 
168

169

170

171

172

173

174

175

176

177

178

179

180

181

182

183

184

185

186

187

188

189

190

191

192

193

two days of treatment with MCL-1 inhibitor, cardiomyocytes became quiescent and stopped beating altogether (Figure S1F-J). These results implicate tachycardia and arrhythmia

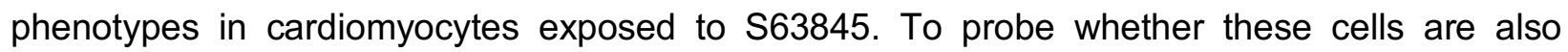
sensitive to BCL-2 inhibition, we also treated hiPSC-CMs with the BCL-2 inhibitor Venetoclax (ABT-199) (Souers et al., 2013). In the same treatment paradigm, ABT-199 had no effect on hiPSC-CM functionality compared to control cells (Figure S1C-G). These results suggest that hiPSC-CMs are highly dependent on MCL-1, but not BCL-2, for function and survival. Intriguingly, we also observed significant changes in the structure and integrity of the actin network and subsequent myofibril organization in cells treated with MCL-1 inhibitor (Figure 2E). hiPSC-CMs displayed poor Z-line organization, lower density of F-actin, and increased presence of stress fibers (Figure 2E). Blinded quantification of F-actin organization revealed that MCL-1 inhibitortreated cells had significantly less organized myofibril structure (Figure 2F).

\section{MCL-1 co-localizes with mitochondrial dynamics proteins in hiPSC-CMs, and S63845} disrupts MCL-1:DRP-1 co-localization.

Since MCL-1 inhibition disrupted mitochondrial network integrity in hiPSC-CMs and MCL-1 depletion affects mitochondrial dynamics proteins (Rasmussen et al., 2018), we next examined the effects of MCL-1 inhibition on the expression levels of key mitochondrial proteins. MCL-1 inhibitor-treated cells had a significant increase in the expression levels of DRP-1 (Figure 3A-B) and MCL-1 (Figure 2C-D). Previous studies using S63845 (Kotschy et al., 2016) also reported the induction of MCL-1 expression. There were no significant changes in the expression levels of phospho-DRP-1 (pDRP-1 S616), OPA1 or TOM20 (Figure 2C-D and Figure S3A). We then assessed whether MCL-1 interacts with these GTPases responsible for maintaining mitochondrial morphology and dynamics using in situ proximity ligation assay (PLA). Our data shows that MCL1 is in close proximity to both DRP-1 and OPA1 (Figure 3E-H). PLA puncta were quantified and normalized to the number of puncta in the control sample (Figure S2B). The co-localization of 
MCL-1 with DRP-1, but not OPA1, was disrupted upon inhibition of MCL-1 with S63845 (Figure 3E-F), suggesting that MCL-1 interacts with DRP-1 through its $\mathrm{BH} 3$ binding groove. Since the interaction with OPA1 was not disturbed (Figure $3 \mathrm{G}-\mathrm{H}$ ), it is possible that MCL-1 interacts with OPA1 either through a different domain, or with a different isoform of OPA1 in hiPSC-CMs than in hPSCs (Rasmussen et al., 2018). Another possibility is that, upon differentiation, the small molecule can no longer penetrate the inner mitochondrial membrane.

DRP-1 is shuttled to the outer mitochondrial membrane upon activation. In our previous study, we showed that MCL-1 depletion decreases the activity of DRP-1 and promotes mitochondrial elongation (Rasmussen et al., 2018). Since MCL-1 inhibition with S63845 appeared to cause mitochondrial fragmentation in cardiomyocytes, we hypothesized that more DRP-1 would be activated and brought to the mitochondria to initiate fission. However, levels of active DRP-1 (pDRP-1 S616) that co-localized with mitochondria decreased in S63845-treated hiPSCCMs (Figure S3A-B). To further assess the disruption of the mitochondrial network caused by MCL-1 inhibition, we employed an assay using a photo-convertible plasmid (mito-tdEos) to assess connectivity and fusion/motility of mitochondria. After photo-conversion, we saw that both the initial converted area and the spread of the converted signal after 20 minutes were significantly decreased (Figure 4A-D). This fragmentation caused by MCL-1 inhibition was also DRP-1 dependent, since knockdown of DRP-1 rescued the increased fragmentation in S63845-treated cells (Figure 4E-F and Figure S3C). The recruitment of DRP-1 to the mitochondria has been proposed to be a critical inducer of mitophagy (Lee et al., 2011; Kageyama et al., 2014; Burman et al., 2017). Thus, an interesting possibility is that inhibition of MCL-1 is decreasing clearing of damaged mitochondria in cardiomyocytes due to the decrease in recruitment of active DRP-1.

\section{MCL-1 inhibition results in iPSC-CM death}

To examine whether iPSC-CMs treated with MCL-1 inhibitor were still sensitive to caspasemediated cell death, we treated the cells with increasing doses of S63845 and examined the 
activation of caspase-3 and caspase-7 in the absence of QVD. Cells responded to S63845 in a dose-dependent manner after 48 hours, with 1-2 $\mu \mathrm{M}$ MCL-1i inducing the most caspase activity (Figure 5A). To examine the possibility that cardiomyocytes were dying independently of caspase3 activation, we used the Incucyte live cell imaging system and indeed found similar levels of cell death with and without caspase inhibition (Figure S4A-B). These results indicate that iPSC-CMs are committing to a caspase-independent cell death in response to MCL-1 inhibition. Previous reports have established that iPSC-derived cardiomyocytes are more similar to immature progenitor cells. To test the possibility that the effects were caused by this immature state, we used a previously published hormone-based method for cardiomyocyte maturation (Figure 5B-C) (Parikh et al., 2017). We tested for caspase-3/7 activation after 24 hours of treatment with increasing doses of $\mathrm{S} 63845$ and detected similar effects of MCL-1 inhibition in hormone-matured hiPSC-CMs and vehicle-treated hiPSC-CMs. (Figure 5D-E). These results together with previous work from other groups (Thomas et al., 2013; Wang et al., 2013) highlight the importance of extended and rigorous testing of safety and potential off-target effects of MCL-1 inhibitors on human cardiomyocytes.

\section{Long-term MCL-1 inhibition, but not BCL-2 inhibition, causes defects in cardiomyocyte} functionality

MCL-1 inhibition has significant effects on hiPSC-CM contractility and functionality when used at higher doses (Figure 2B-D and Figure S1C-G). To test if MCL-1 inhibition still depletes cardiac functionality at lower doses, we treated hiPSC-CMs for two weeks (with treatments every two days) with $100 \mathrm{nM}$ S63845. We also treated the cells with the BCL-2 inhibitor ABT-199 (100 $\mathrm{nM}$ ) and a combination of S63845 + ABT-199 (100 nM each). While there were no significant differences between treatments in the spike slope mean (Figure 6B) and beat period mean (Figure S5A), either MCL-1 inhibition alone or the combination treatment significantly disrupted hiPSCCM spike amplitude mean (Figure 6A), conduction velocity mean (Figure 6C), max delay mean 
(Figure 6D), propagation consistency (Figure 6E), and field potential duration (Figure S5B). Cells treated with ABT-199 appeared healthy and were functionally similar to control cells throughout the experiment (Figure 6A-E and Figure S5A-B). Cells displayed mitochondrial network and actin disruption in the S63845-treated condition, and even more severe phenotypes were observed in cells treated with both inhibitors when compared to control cells (Figure 6F-I and Figure S5C-F). BCL-2 inhibition had little effect on mitochondrial network organization and virtually no effect on myofibril organization (Figure $6 \mathrm{H}$ and Figure S5E). These results further support the idea that

253 MCL-1 plays an important role in the mitochondrial homeostasis of cardiomyocytes. It would be of interest to determine whether MCL-1 function in mitochondrial dynamics affects the maturation of iPSC-CMs or heart development in vivo (Kasahara et al., 2013; Feaster et al., 2015; Parikh et al., 2017). We speculate that other determinants of mitochondrial homeostasis, including mitochondrial biogenesis and mitophagy, may be affected by MCL-1 deficiency in these cells as they mature.

Whether the function of MCL-1 in mitochondrial dynamics is critical for maintaining the metabolic profile of iPSC-CMs is not known. Studies from our laboratory show that inhibition of MCL-1 induces the differentiation of iPSCs (Rasmussen et al., 2018), which is likely associated with changes in metabolism to support cell-type specific processes (Folmes et al., 2016). Since mitochondrial morphology is tightly coupled to cellular respiration via integrity of the ETC, future studies will aim to investigate the metabolic changes that occur when MCL-1 is deleted in iPSCCMs. Cardiac contractions depend on energy from these metabolic pathways, and thus cardiac mitochondria are forced to work constantly and likely require strict quality control mechanisms to

267 maintain a functioning state (Dorn et al., 2015). This quality control process could depend in part 268 on MCL-1. In support of this idea, our studies indicate that MCL-1 activity is essential for iPSC269 CM viability and maturation, which could be linked to MCL-1's non-apoptotic function at the 270 mitochondrial matrix. Our results emphasize the need for a more complete molecular 271 understanding of MCL-1's mechanism of action in human cardiomyocytes as it may reveal new 
272 approaches to prevent potential cardiac toxicities associated with chemotherapeutic inhibition of

273 MCL-1.

274

Materials and Methods

Cell Culture

278 Human induced pluripotent stem cell-derived cardiomyocytes (iCell Cardiomyocytes ${ }^{2}$ ) were 279 obtained from Cellular Dynamics International (\#CMC-100-012-000.5). Cells were thawed 280 according the manufacturer protocol in iCell Plating medium. Briefly, cells were thawed and plated on $0.1 \%$ gelatin at 50,000 cells/well in 96 -well plates. Cells were maintained at $37^{\circ} \mathrm{C}$ and $5 \% \mathrm{CO}_{2}$ and fed every other day with iCell Cardiomyocyte Maintenance medium (Cellular Dynamics International \#M1003). For knockdown experiments, wells were coated with $5 \mu \mathrm{g} / \mathrm{mL}$ fibronectin

284 (Corning \#354008) 1 hour prior to plating. For functional experiments using the Axion bioanalyzer, cells were plated on $50 \mu \mathrm{g} / \mathrm{mL}$ fibronectin in a 48-well CytoView MEA plate (Axion Biosystems \#M768-tMEA-48B). For imaging experiments, cells were re-plated on glass-bottom $35 \mathrm{~mm}$ dishes

287 (Cellvis \#D35C4-20-1.5-N) coated with $10 \mu \mathrm{g} / \mathrm{mL}$ fibronectin. For live-cell imaging, cells were maintained at $37^{\circ} \mathrm{C}$ with $5 \% \mathrm{CO}^{2}$ in a stage top incubator (Tokai Hit).

\section{Cell Treatments}

291 All treatments were added directly to cells in iCell Cardiomyocyte Maintenance media. The pan292 caspase inhibitor Q-VD-OPh (SM Biochemicals \#SMPH001) was added to cells at a concentration 293 of $25 \mu \mathrm{M}$. The small molecule MCL-1 inhibitor derivative (S63845) was a gift from Joseph 294 Opferman (St. Jude's Children Hospital). ABT-199 was purchased from Active Biochemicals (\#A295 1231). All stock solutions were prepared in DMSO. 


\section{RNAi and Plasmid Transfection}

Commercially available siRNA targeting DRP-1 (Thermo Fisher Scientific \# AM51331) was used

to generate transient knockdowns in hiPSC-CMs. Cells were seeded at 50,000 cells per well in a

96-well plate coated with $5 \mu \mathrm{g} / \mathrm{mL}$ fibronectin. Cells were transfected as per the manufacturer protocol using TransIT-TKO Transfection Reagent (Mirus Bio \#MIR2154) in iCell maintenance media containing 25uM Q-VD-OPh. To increase knockdown efficiency, the transfection was repeated 48 hours later. Cells were left to recover for an additional 24 hours in fresh media containing 25uM Q-VD-OPh. Cells were lysed for Western blot or re-plated on glass-bottom 35 $\mathrm{mm}$ dishes and fixed for analysis by immunofluorescence. Silencer Select Negative Control No. 1 (Thermo Fisher Scientific \# 4390843) was used as a control.

Plasmid encoding mito-tdEos (Addgene \#57644) was transfected using ViaFect (Promega \#E4981) as described in the manufacturer protocol. Cells were maintained until optimal transfection efficiency was reached before cells were imaged.

\section{Immunofluorescence}

313 For immunofluorescence, cells were fixed with $4 \%$ paraformaldehyde for 20 min and

314 permeabilized in $1 \%$ Triton-X-100 for $10 \mathrm{~min}$ at room temperature. After blocking in $10 \%$ BSA, 315 cells were treated with primary and secondary antibodies using standard methods. Cells were 316 mounted in Vectashield (Vector Laboratories \#H-1000) prior to imaging. Primary antibodies used 317 include Alexa Fluor-488 Phalloidin (Thermo Fisher Scientific \#A12379), mouse anti-mtCO2 318 (Abcam \#ab110258), rabbit anti-pDRP-1 S616 (Cell Signaling Technologies \#3455S). For 319 Incucyte experiments, nuclei were visualized using NucLight Rapid Red Reagent (Essen 320 Bioscience \#4717). Alexa Fluor-488 (Thermo Fisher Scientific \#A11008) and Alexa Fluor-568 321 (Thermo Fisher Scientific \#A11011) were used as secondary antibodies. MitoTracker Red 322 CMXRos (Thermo Fisher Scientific \#M7512) added at $100 \mathrm{nM}$ was used to visualize mitochondria 323 in PLA experiments. 


\section{Western blot}

326 Gel samples were prepared by mixing cell lysates with LDS sample buffer (Life Technologies, $327 \quad$ \#NP0007) and 2-Mercaptoethanol (BioRad \#1610710) and boiled at $95^{\circ} \mathrm{C}$ for 5 minutes. Samples 328 were resolved on 4-20\% Mini-PROTEAN TGX precast gels (BioRad \#4561096) and transferred 329 onto PVDF membrane (BioRad \#1620177). Antibodies used for Western blotting are as follows:

330 DRP-1 (Cell Signaling Technologies \#8570S), pDRP-1 S616 (Cell Signaling Technologies \#4494), OPA1 (Cell Signaling Technologies \#67589S), MCL-1 (Cell Signaling Technologies \#94296S), TOM20 (Cell Signaling Technologies \# 42406S), and a-Tubulin (Sigma \# 05-829).

\section{Impedance assays}

335 The Axion Biosystems analyzer was used to measure contractility and impedance in iPSC-CMs. Cells were plated on 48-well CytoView MEA plates and maintained for 10 days before treatment

337 and recordings. Recordings were taken for 5 minutes approximately two hours after media 338 change.Cells were assayed using the standard cardiac analog mode setting with $12.5 \mathrm{kHz}$ 339 sampling frequency to measure spontaneous cardiac beating. The Axion instrument was controlled using Maestro Pro firmware version 1.5.3.4. Cardiac beat detector settings are as

341 follows:

\begin{tabular}{|l|l|}
\hline Beat Detection Threshold & $300 \mu \mathrm{V}$ \\
\hline Min. Beat Period & $250 \mathrm{~ms}$ \\
\hline Max. Beat Period & $5 \mathrm{~s}$ \\
\hline $\begin{array}{l}\text { Synchronized Beat Maximum } \\
\text { Propagation Delay }\end{array}$ & $30 \mathrm{~ms}$ \\
\hline Minimum Active Channels Ratio & $50.00 \%$ \\
\hline Running Average Beat Count & 10 \\
\hline
\end{tabular}




\section{Proximity Ligation Assay (PLA)}

344 Cells were seeded onto fibronectin-coated 8-chamber MatTek glass slides (\#CCS-8) at 10,000

345 cells/chamber. After treatments, cells were fixed in 4\% PFA for 20 min and permeabilized in 1\%

346 Triton-100-X for $10 \mathrm{~min}$ at room temperature. Following fixation, the DuoLink proximity ligation

347 assay (Sigma \#DUO92014) was performed as per manufacturer protocol. The primary antibodies

348 were incubated overnight at $4^{\circ} \mathrm{C}$ and are as follows: mouse anti-MCL-1 (Proteintech \# 66026-1-

349 lg), rabbit anti-DRP-1 (Cell Signaling Technologies \#8570S), rabbit anti-OPA1 (Cell Signaling

350 Technologies \#67589S), and control containing no primary antibody.

351

352

353

354

355

356

357

358

359

360

361

362

\section{Photoconversion experiments}

Mitochondrial network connectivity and fusion was assayed using photo-conversion of mitochondria tagged with Mito-tdEos. Photo-conversion was performed on a Nikon Eclipse Ti inverted widefield microscope equipped with a 1.45 NA 100X Oil objective. Briefly, a stimulation region was closing down the field diaphragm and using the filter to shine $405 \mathrm{~nm}$ light for 6 seconds. Images for the converted (TxRed) and unconverted (FITC) were acquired before and after stimulation. The TxRed image before stimulation was used to subtract background from the post-stimulation images, followed by thresholding and automated measurement in Fiji (Schindelin et al., 2012). The initial converted area immediately after stimulation was used as a measure of connectivity, while the spread of the converted signal after 20 minutes was used as a measure of fusion/motility. The initial converted area (TxRed channel) was normalized to the total unconverted area (FITC channel) to account for any initial variation in the total mitochondrial area.

\section{Image acquisition}

Super-resolution images for Figures 1 and 2 were acquired using a GE DeltaVision OMX microscope equipped with a 1.42 NA 60X Oil objective and a sCMOS camera. Super-resolution images for Figure 6 were acquired using a Nikon SIM microscope equipped with a 1.49 NA 100x 
Oil objective an Andor DU-897 EMCCD camera. Images for Figures S3, 4, and S5 were acquired on a Nikon Eclipse Ti inverted widefield microscope equipped with a 1.45 NA 100X Oil or 1.40 NA 60X Oil objective. Image processing and quantification was performed using Fiji. Measurement of cell number to assay cell death was performed on a Incucyte S3 live cell imaging system (Essen Bioscience) equipped with a 10X objective. Images for the PLA experiments were acquired on a Nikon spinning disk confocal microscope equipped with a 1.40 NA 60X Oil objective.

\section{Statistical Analysis}

377 All experiments were performed with a minimum of 3 biological replicates. Statistical significance 378 was determined by unpaired, two-tailed Student's t-test or by one- or two-way ANOVA as appropriate for each experiment. GraphPad Prism v8.1.2 was used for all statistical analysis and data visualization.

381 Error bars in all bar graphs represent standard error of the mean or standard deviation as described for each figure, while Tukey plots were represented with boxes (with median, Q1, Q3 percentiles), whiskers (minimum and maximum values within 1.5 times interquartile range) and solid circles (outliers). No outliers were removed from the analyses.

For MEA experiments, means from triplicate biological replicates (each with three technical replicate wells) for each measurement were plotted and significance was determined by two-way ANOVA.

For PLA experiments, images were quantified using Fiji. Briefly, background noise levels were subtracted, and number of puncta per ROI was normalized to mitochondrial area. ROls in at least 5 cells per condition were quantified in three independent experiments.

391 Quantification of actin organization was performed in a blinded fashion and percentages of each 392 category are displayed. Cell viability measured using the Incucyte live cell imaging system was 393 performed by automatic segmentation of nuclei in Fiji, followed by subtraction of dead cells as 394 indicated by fragmented nuclei and rounded phenotype. 


\section{Acknowledgements}

We would like to thank Dr. Kevin Ess for providing access to the Axion Biosystems MEA analyzer,

397 John Snow for providing critical technical support with the Axion analyzer, Bryan Millis for

398 providing expertise with high resolution microscopy, and Stellan Riffle for technical support. This

399 work was supported by 1R35 GM128915-01 NIGMS (to VG), 4R00CA178190 NCl (to VG),

400 1R21CA227483-01A1 NCI (to VG), 19PRE34380515 AHA (to MLR), 18PRE33960551 (to NT),

401 and R35 GM125028-01 (to DTB). The Vanderbilt Cell Imaging Shared Resource is supported by

402 NIH grants 1S10OD012324-01 and 1S100D021630-01.

403

404 The authors declare no competing financial interests.

405

406

\section{Author contributions}

407 V. Gama, M. Rasmussen and N. Taneja conceived the study, designed experiments, interpreted 408 data, and wrote the manuscript. M. Rasmussen and N. Taneja designed and carried out all the

409 cell biology experiments, with input from D. Burnette, A. Neininger, L. Wang, and L. Shi. V. Gama designed and supervised the project. The manuscript was prepared by M. Rasmussen and V.

411 Gama, and revised by N. Taneja and D. Burnette. D. Burnette and B. Knollmann provided vital 412 reagents and critical expertise.

413

414 The authors declare no competing interests. 
Figure 1: MCL-1 inhibition causes mitochondrial fragmentation. (A) Maximum intensity projection showing mitochondria (mt-CO2) and myofibril (F-actin) organization in an untreated hiPSC-CM. Rainbow LUT shown to denote Z-depth. Scale: $10 \mu \mathrm{m}$. (B) Schematic of cell treatment paradigm used throughout this study. Structured Illumination Microscopy (SIM) was used for acquisition of

427 all super-resolution images. (C) hiPSC-CMs were treated with vehicle (DMSO) or $2 \mu \mathrm{M}$ S63845

428 and Q-VD-Oph (QVD). Vehicle-treated cells have elongated mitochondria assembled in networks; MCL-1 inhibition causes mitochondria to become fragmented and disorganized. Insets show magnification of individual mitochondria morphology. Scale: $10 \mu \mathrm{m}$. Representative images are shown for all panels.

Figure 2: MCL-1 inhibition causes disruption of myofibrils and functional defects. (A) Schematic of Axion Biosystems MEA paradigm for recording cardiac performance in live cells. hiPSC-CMs were plated on a CytoView MEA plate (Axion Biosystems) and treated with either vehicle (DMSO) for 5 minutes; (B) beat period irregularity was increased in MCL-1i-treated cells, while spike amplitude mean and spike slope mean were decreased (C-D). (E) Vehicle-treated hiPSC-CMs have organized myofibril structure as shown by maximum intensity projections. hiPSC-CMs treated with $2 \mu \mathrm{M} \mathrm{MCL}-1 i$ (S63845) and QVD have myofibrils that are unorganized and poorly

441 defined Z-lines. Scale: $10 \mu \mathrm{m}$. Representative images are shown for all panels. (F) Quantification 442 of myofibril structure phenotypes represented in Figure 2E ( $n=\sim 80$ cells from 3 separate 443 experiments).

445 Figure 3: MCL-1 interacts with mitochondrial dynamics proteins. (A) Western blot showing DRP4461 activity in hiPSC-CMs treated with S63845 + QVD. (B) Quantification of DRP-1 and pDRP-1 
447

448

449

450

451

452

453

454

455

456

457

458

459

460

461

462

463

464

465

466

467

468

469

470

471

S616 band density relative to a-tubulin. (C) Western blot showing OPA1, MCL-1, and TOM20 levels in hiPSC-CMs treated with S63845 + QVD. (D) Quantification of OPA1 and MCL-1 band density relative to $\alpha$-tubulin. Images from PLA showing representative ROIs showing MCL-1:DRP1 (E) or MCL-1:OPA1 (G) puncta in vehicle- or S63845-treated hiPSC-CMs (Scale: $5 \mu \mathrm{m}$ ). Quantification of PLA puncta from MCL-1:DRP-1 (F) or MCL-1:OPA1 $(\mathrm{H})$ interactions $(\mathrm{n}=10-15$ images per condition from 3 independent experiments). All error bars indicate $\pm S D$.

Figure 4: MCL-1 inhibition results in mitochondrial fragmentation through a DRP-1 dependent manner. (A) Vehicle- and (B) S63845-treated hiPSC-CMs were transfected with Mito-tdEos and a small area was photo-converted (see methods). Cells were imaged for 20 minutes-postconversion to assess mitochondrial network connectivity. Quantification of $(C)$ initial converted area normalized to total unconverted area and (D) fold change in converted area after 20 minutes from Figure 4A-B. (E) Quantification of initial converted area normalized to total unconverted area in hiPSC-CMs treated with si-Control (si-Cont) $\pm \mathrm{MCL}-1 i(2 \mu \mathrm{M})$ and si-DRP-1 \pm MCL-1i $(2 \mu \mathrm{M})$. (F) Quantification of fold change in converted area after 20 minutes in same treatments from Figure 4E. Boxplots show Tukey whiskers.

Figure 5: hiPSC-CMs commit to intrinsic apoptosis after MCL-1 inhibition. (A) iCell hiPSC-CMs were treated with increasing doses of $\mathbf{S} 63845$ for 48 hours before caspase activity was measured by CaspaseGlo 3/7 assay (Promega). (B) Schematic of maturation protocol for hiPSC-CMs shown in Figure 1C. (C) hiPSC-CMs treated with Dex (dexamethasone) and T3 (triiodothyronine) display more mature phenotype compared to vehicle-treated control cells. (D) Vehicle- or (E) Dex+T3treated hiPSC-CMs were exposed to $\mathbf{S} 63845$ at increasing doses for 24 hours. Caspase activity was measured as in Figure 1A. 
472 Figure 6: Chronic inhibition of MCL-1, but not BCL-2, results in cardiac activity defects. hiPSC-

473 CMs were treated every 2 days with DMSO (blue), 100 nM S63845 (orange), 100 nM ABT-199

474 (green), or both inhibitors (magenta) for 14 days. MEA plate was recorded 2 hours-post-treatment

475 for 5 minutes and results were normalized to baseline recording for each respective well. Results

476 of recordings for spike amplitude mean (A), spike slope mean (B), conduction velocity mean (C),

477 max delay mean (D), and propagation consistency (E) are shown. P-values show significance as

478 follows: ${ }^{*}=$ DMSO vs. S63845, $\dagger=$ DMSO vs. Combination, $\#=$ S63845 vs. ABT-199, $\ddagger=$ S63845

479 vs. Combination, $\bullet=$ ABT-199 vs. Combination. One symbol indicates $p=<0.05$, two symbols

480 indicate $p=<0.01$. Error bars indicate \pm SEM. (F-I) Mitochondria and F-actin were imaged at the

481 end of the treatment paradigm in Figure 6A-E. Representative images are shown of cells treated

482 with DMSO (F), 100 nM MCL-1i (S63845) (G), 100 nM BCL-2i (ABT-199) (H), and 100 nM MCL-

$4831 i+100 \mathrm{nM} \mathrm{BCL}-2 i$ (Combination) (I). Scale: $10 \mu \mathrm{m}$. 


\section{References}

485

486

487

488

489

490

491

492

493

494

495

496

497

498

499

500

501

502

503

504

505

506

507

508

Beroukhim, R., Mermel, C.H., Porter, D., Wei, G., Raychaudhuri, S., Donovan, J., Barretina, J., Boehm, J.S., Dobson, J., Urashima, M., Mc Henry, K.T., Pinchback, R.M., Ligon, A.H., Cho, Y.-J., Haery, L., Greulich, H., Reich, M., Winckler, W., Lawrence, M.S., Weir, B.A., Tanaka, K.E., Chiang, D.Y., Bass, A.J., Loo, A., Hoffman, C., Prensner, J., Liefeld, T., Gao, Q., Yecies, D., Signoretti, S., Maher, E., Kaye, F.J., Sasaki, H., Tepper, J.E., Fletcher, J.A., Tabernero, J., Baselga, J., Tsao, M.-S., Demichelis, F., Rubin, M.A., Janne, P.A., Daly, M.J., Nucera, C., Levine, R.L., Ebert, B.L., Gabriel, S., Rustgi, A.K., Antonescu, C.R., Ladanyi, M., Letai, A., Garraway, L.A., Loda, M., Beer, D.G., True, L.D., Okamoto, A., Pomeroy, S.L., Singer, S., Golub, T.R., Lander, E.S., Getz, G., Sellers, W.R., Meyerson, M., 2010. The landscape of somatic copy-number alteration across human cancers. Nature 463, 899-905. https://doi.org/10.1038/nature08822

Buggisch, M., Ateghang, B., Ruhe, C., Strobel, C., Lange, S., Wartenberg, M., Sauer, H., 2007. Stimulation of ES-cell-derived cardiomyogenesis and neonatal cardiac cell proliferation by reactive oxygen species and NADPH oxidase. J. Cell Sci. 120, 885-894. https://doi.org/10.1242/jcs.03386

Burman, J.L., Pickles, S., Wang, C., Sekine, S., Vargas, J.N.S., Zhang, Z., Youle, A.M., Nezich, C.L., Wu, X., Hammer, J.A., Youle, R.J., 2017. Mitochondrial fission facilitates the selective mitophagy of protein aggregates. J. Cell Biol. 216, 3231-3247. https://doi.org/10.1083/jcb.201612106

Burté, F., Carelli, V., Chinnery, P.F., Yu-Wai-Man, P., 2015. Disturbed mitochondrial dynamics and neurodegenerative disorders. Nat. Rev. Neurol. 11, 11-24. https://doi.org/10.1038/nrneurol.2014.228

Chan, D.C., 2007. Mitochondrial Dynamics in Disease. N. Engl. J. Med. 356, 1707-1709. https://doi.org/10.1056/NEJMp078040 
Chipuk, J.E., Moldoveanu, T., Llambi, F., Parsons, M.J., Green, D.R., 2010. The BCL-2 Family Reunion. Mol. Cell 37, 299-310. https://doi.org/10.1016/j.molcel.2010.01.025

Cho, S.W., Park, J., Heo, H.J., Park, S., Song, S., Kim, I., Han, Y., Yamashita, J.K., Youm, J.B., Han, J., Koh, G.Y., 2014. Dual Modulation of the Mitochondrial Permeability Transition Pore and Redox Signaling Synergistically Promotes Cardiomyocyte Differentiation From Pluripotent Stem Cells. J. Am. Heart Assoc. 3. https://doi.org/10.1161/JAHA.113.000693

Clements, M., Thomas, N., 2014. High-Throughput Multi-Parameter Profiling of Electrophysiological Drug Effects in Human Embryonic Stem Cell Derived Cardiomyocytes Using Multi-Electrode Arrays. Toxicol. Sci. $\quad 140, \quad 445-461$. https://doi.org/10.1093/toxsci/kfu084

Cohen, N.A., Stewart, M.L., Gavathiotis, E., Tepper, J.L., Bruekner, S.R., Koss, B., Opferman, J.T., Walensky, L.D., 2012. A Competitive Stapled Peptide Screen Identifies a Selective Small Molecule that Overcomes MCL-1-Dependent Leukemia Cell Survival. Chem. Biol. 19, 11751186. https://doi.org/10.1016/j.chembiol.2012.07.018

Dorn, G.W., 2013. Mitochondrial dynamics in heart disease. Biochim. Biophys. Acta BBA - Mol. Cell Res. 1833, 233-241. https://doi.org/10.1016/j.bbamcr.2012.03.008

Dorn, G.W., Vega, R.B., Kelly, D.P., 2015. Mitochondrial biogenesis and dynamics in the developing and diseased heart. Genes Dev. 29, 1981-1991. https://doi.org/10.1101/gad.269894.115

Dumitru, R., Gama, V., Fagan, B.M., Bower, J.J., Swahari, V., Pevny, L.H., Deshmukh, M., 2012. Human Embryonic Stem Cells Have Constitutively Active Bax at the Golgi and Are Primed to Undergo Rapid Apoptosis. Mol. Cell 46, 573-583. https://doi.org/10.1016/j.molcel.2012.04.002

Feaster, T.K., Cadar, A.G., Wang, L., Williams, C.H., Chun, Y.W., Hempel, J.E., Bloodworth, N., Merryman, W.D., Lim, C.C., Wu, J.C., Knollmann, B.C., Hong, C.C., 2015. Matrigel Mattress: A Method for the Generation of Single Contracting Human-Induced Pluripotent Stem Cell- 
Res.

117,

995-1000.

Folmes, C.D., Ma, H., Mitalipov, S., Terzic, A., 2016. Mitochondria in pluripotent stem cells: stemness regulators and disease targets. Curr. Opin. Genet. Dev. 38, 1-7. https://doi.org/10.1016/j.gde.2016.02.001

Friedman, J.R., Nunnari, J., 2014. Mitochondrial form and function. Nature 505, 335-343. https://doi.org/10.1038/nature12985

Galloway, C.A., Yoon, Y., 2015. Mitochondrial Dynamics in Diabetic Cardiomyopathy. Antioxid. Redox Signal. 22, 1545-1562. https://doi.org/10.1089/ars.2015.6293

Gama, V., Deshmukh, M., 2012. Human embryonic stem cells: living on the edge. Cell Cycle Georget. Tex 11, 3905-3906. https://doi.org/10.4161/cc.22233

Guo, L., Eldridge, S., Furniss, M., Mussio, J., Davis, M., 2018. Role of Mcl-1 in regulation of cell Heart Fail. Rev. 21, 103-116. https://doi.org/10.1007/s10741-015-9524-5

Imahashi, K., Schneider, M.D., Steenbergen, C., Murphy, E., 2004. Transgenic Expression of Bcl2 Modulates Energy Metabolism, Prevents Cytosolic Acidification During Ischemia, and Reduces Ischemia/Reperfusion Injury. Circ.

Res.

95 , 734-741. https://doi.org/10.1161/01.RES.0000143898.67182.4c

Itoh, K., Nakamura, K., lijima, M., Sesaki, H., 2013. Mitochondrial dynamics in neurodegeneration. 
Parkin-independent mitophagy requires Drp1 and maintains the integrity of mammalian heart and brain. EMBO J. 33, 2798-2813. https://doi.org/10.15252/embj.201488658

Kasahara, A., Cipolat, S., Chen, Y., Dorn, G.W., Scorrano, L., 2013. Mitochondrial Fusion Directs Cardiomyocyte Differentiation via Calcineurin and Notch Signaling. Science 342, 734-737. https://doi.org/10.1126/science.1241359

Kasahara, A., Scorrano, L., 2014. Mitochondria: from cell death executioners to regulators of cell differentiation. Trends Cell Biol. 24, 761-770. https://doi.org/10.1016/j.tcb.2014.08.005

Kotschy, A., Szlavik, Z., Murray, J., Davidson, J., Maragno, A.L., Le Toumelin-Braizat, G., Chanrion, M., Kelly, G.L., Gong, J.-N., Moujalled, D.M., Bruno, A., Csekei, M., Paczal, A., Szabo, Z.B., Sipos, S., Radics, G., Proszenyak, A., Balint, B., Ondi, L., Blasko, G., Robertson, A., Surgenor, A., Dokurno, P., Chen, I., Matassova, N., Smith, J., Pedder, C., Graham, C., Studeny, A., Lysiak-Auvity, G., Girard, A.-M., Gravé, F., Segal, D., Riffkin, C.D., Pomilio, G., Galbraith, L.C.A., Aubrey, B.J., Brennan, M.S., Herold, M.J., Chang, C., Guasconi, G., Cauquil, N., Melchiore, F., Guigal-Stephan, N., Lockhart, B., Colland, F., Hickman, J.A., Roberts, A.W., Huang, D.C.S., Wei, A.H., Strasser, A., Lessene, G., Geneste, O., 2016. The MCL1 inhibitor S63845 is tolerable and effective in diverse cancer models. Nature 538, 477482. https://doi.org/10.1038/nature19830

Kozopas, K.M., Yang, T., Buchan, H.L., Zhou, P., Craig, R.W., 1993. MCLI, a gene expressed in programmed myeloid cell differentiation, has sequence similarity to BCL2. Proc Natl Acad Sci USA 5 .

Lee, Y., Lee, H.-Y., Hanna, R.A., Gustafsson, Å.B., 2011. Mitochondrial autophagy by Bnip3 involves Drp1-mediated mitochondrial fission and recruitment of Parkin in cardiac myocytes. Am. J. Physiol. - Heart Circ. Physiol. 301, H1924-H1931. https://doi.org/10.1152/ajpheart.00368.2011

Letai, A., 2016. S63845, an MCL-1 Selective BH3 Mimetic: Another Arrow in Our Quiver. Cancer Cell 30, 834-835. https://doi.org/10.1016/j.ccell.2016.11.016 
586

587

588

589

590

591

592

593

594

595

596

597

598

599

600

601

602

603

604

605

606

607

608

609

610

611

Morciano, G., Giorgi, C., Balestra, D., Marchi, S., Perrone, D., Pinotti, M., Pinton, P., 2016. Mcl-1 involvement in mitochondrial dynamics is associated with apoptotic cell death. Mol. Biol. Cell 27, 20-34. https://doi.org/10.1091/mbc.E15-01-0028

Murray, T.V.A., Ahmad, A., Brewer, A.C., 2014. Reactive oxygen at the heart of metabolism. Trends Cardiovasc. Med. 24, 113-120. https://doi.org/10.1016/j.tcm.2013.09.003

Murriel, C.L., Churchill, E., Inagaki, K., Szweda, L.I., Mochly-Rosen, D., 2004. Protein Kinase Cס Activation Induces Apoptosis in Response to Cardiac Ischemia and Reperfusion Damage A MECHANISM INVOLVING BAD AND THE MITOCHONDRIA. J. Biol. Chem. 279, 4798547991. https://doi.org/10.1074/jbc.M405071200

Opferman, J.T., 2016. Attacking Cancer's Achilles Heel: Antagonism of Anti-Apoptotic BCL-2 Family Members. FEBS J. 283, 2661-2675. https://doi.org/10.1111/febs.13472

Parikh, S.S., Blackwell, D.J., Gomez-Hurtado, N., Frisk, M., Wang, L., Kim, K., Dahl, C.P., Fiane, A., Tønnessen, T., Kryshtal, D.O., Louch, W.E., Knollmann, B.C., 2017. Thyroid and Glucocorticoid Hormones Promote Functional T-Tubule Development in Human-Induced Pluripotent Stem Cell-Derived Cardiomyocytes. Circ. Res. 121, 1323-1330. https://doi.org/10.1161/CIRCRESAHA.117.311920

Perciavalle, R.M., Opferman, J.T., 2013. Delving Deeper: MCL-1's Contributions to Normal and Cancer Biology. Trends Cell Biol. 23, 22-29. https://doi.org/10.1016/j.tcb.2012.08.011

Perciavalle, R.M., Stewart, D.P., Koss, B., Lynch, J., Milasta, S., Bathina, M., Temirov, J., Cleland, M.M., Pelletier, S., Schuetz, J.D., Youle, R.J., Green, D.R., Opferman, J.T., 2012. Antiapoptotic MCL-1 localizes to the mitochondrial matrix and couples mitochondrial fusion to respiration. Nat. Cell Biol. 14, 575-583. https://doi.org/10.1038/ncb2488

Rasmussen, M.L., Kline, L.A., Park, K.P., Ortolano, N.A., Romero-Morales, A.I., Anthony, C.C., Beckermann, K.E., Gama, V., 2018. A Non-apoptotic Function of MCL-1 in Promoting Pluripotency and Modulating Mitochondrial Dynamics in Stem Cells. Stem Cell Rep. 10, 684692. https://doi.org/10.1016/j.stemcr.2018.01.005 
612

613

614

615

616

617

618

619

620

621

622

623

624

625

626

627

628

629

630

631

632

633

634

635

636

637

Reynolds, J.E., Li, J., Craig, R.W., Eastman, A., 1996. BCL-2 and MCL-1 Expression in Chinese Hamster Ovary Cells Inhibits Intracellular Acidification and Apoptosis Induced by Staurosporine. Exp. Cell Res. 225, 430-436. https://doi.org/10.1006/excr.1996.0194

Rinkenberger, J.L., Horning, S., Klocke, B., Roth, K., Korsmeyer, S.J., 2000. Mcl-1 deficiency results in peri-implantation embryonic lethality. Genes Dev. 6.

Schindelin, J., Arganda-Carreras, I., Frise, E., Kaynig, V., Longair, M., Pietzsch, T., Preibisch, S., Rueden, C., Saalfeld, S., Schmid, B., Tinevez, J.-Y., White, D.J., Hartenstein, V., Eliceiri, K., Tomancak, P., Cardona, A., 2012. Fiji: an open-source platform for biological-image analysis. Nat. Methods 9, 676-682. https://doi.org/10.1038/nmeth.2019

Song, M., Franco, A., Fleischer, J.A., Zhang, L., Dorn, G.W., 2017. Abrogating Mitochondrial Dynamics in Mouse Hearts Accelerates Mitochondrial Senescence. Cell Metab. 26, 872883.e5. https://doi.org/10.1016/j.cmet.2017.09.023

Souers, A.J., Leverson, J.D., Boghaert, E.R., Ackler, S.L., Catron, N.D., Chen, J., Dayton, B.D., Ding, H., Enschede, S.H., Fairbrother, W.J., Huang, D.C.S., Hymowitz, S.G., Jin, S., Khaw, S.L., Kovar, P.J., Lam, L.T., Lee, J., Maecker, H.L., Marsh, K.C., Mason, K.D., Mitten, M.J., Nimmer, P.M., Oleksijew, A., Park, C.H., Park, C.-M., Phillips, D.C., Roberts, A.W., Sampath, D., Seymour, J.F., Smith, M.L., Sullivan, G.M., Tahir, S.K., Tse, C., Wendt, M.D., Xiao, Y., Xue, J.C., Zhang, H., Humerickhouse, R.A., Rosenberg, S.H., Elmore, S.W., 2013. ABT-199, a potent and selective BCL-2 inhibitor, achieves antitumor activity while sparing platelets. Nat. Med. 19, 202-208. https://doi.org/10.1038/nm.3048

Thomas, L.W., Lam, C., Edwards, S.W., 2010. Mcl-1; the molecular regulation of protein function. FEBS Lett. 584, 2981-2989. https://doi.org/10.1016/j.febslet.2010.05.061

Thomas, R.L., Roberts, D.J., Kubli, D.A., Lee, Y., Quinsay, M.N., Owens, J.B., Fischer, K.M., Sussman, M.A., Miyamoto, S., Gustafsson, Å.B., 2013. Loss of MCL-1 leads to impaired autophagy and rapid development of heart failure. Genes Dev. 27, 1365-1377. https://doi.org/10.1101/gad.215871.113 
Walensky, L.D., 2012. Stemming Danger with Golgified BAX. Mol. Cell 46, 554-556. https://doi.org/10.1016/j.molcel.2012.05.034

Wang, X., Bathina, M., Lynch, J., Koss, B., Calabrese, C., Frase, S., Schuetz, J.D., Rehg, J.E., Opferman, J.T., 2013. Deletion of MCL-1 causes lethal cardiac failure and mitochondrial dysfunction. Genes Dev. 27, 1351-1364. https://doi.org/10.1101/gad.215855.113

Westermann, B., 2010. Mitochondrial fusion and fission in cell life and death. Nat. Rev. Mol. Cell Biol. 11, 872-884. https://doi.org/10.1038/nrm3013

Yang, T., Buchan, H.L., Townsend, K.J., Craig, R.W., 1996. MCL-1, a member of the BCL-2 family, is induced rapidly in response to signals for cell differentiation or death, but not to signals for cell proliferation. J. Cell. Physiol. 166, 523-536. https://doi.org/10.1002/(SICI)1097-4652(199603)166:3<523::AID-JCP7>3.0.CO;2-R

Zhang, J., Nuebel, E., Daley, G.Q., Koehler, C.M., Teitell, M.A., 2012. Metabolic Regulation in Pluripotent Stem Cells during Reprogramming and Self-Renewal. Cell Stem Cell 11, 589595. https://doi.org/10.1016/j.stem.2012.10.005 
Figure 1

bioRxiv preprint doi: https://doi.org/10.1101/743922; this version posted August 22, 2019. The copyright holder for this preprint (which was not ceAfied by peer review) is the author/funder, who has granted bioRxiv a license to display the preprint in perpetuity. It is made available under $\mathrm{mt}-\mathrm{CO} 2$ aCC-BY-NC-ND 4 F-actintin

Merge
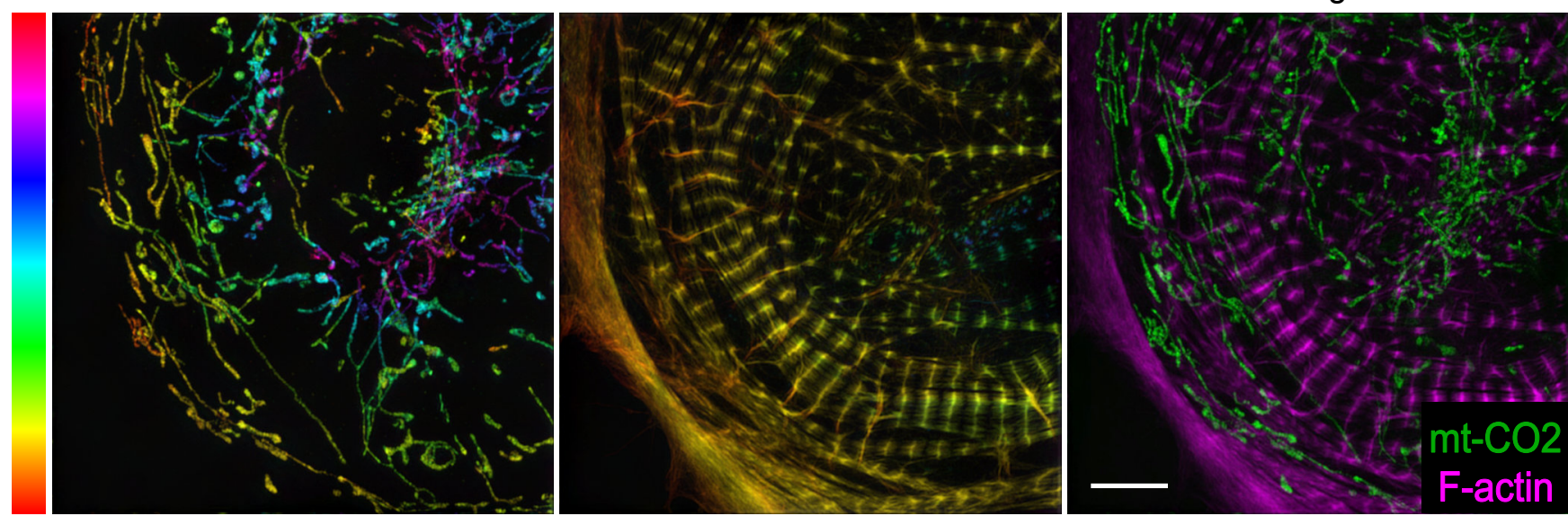

B
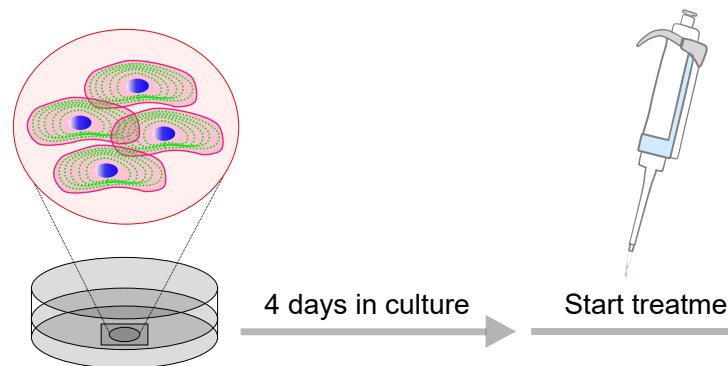

Start treatments

Immunocytochemistry

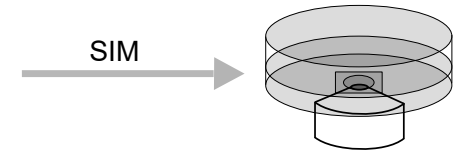

C

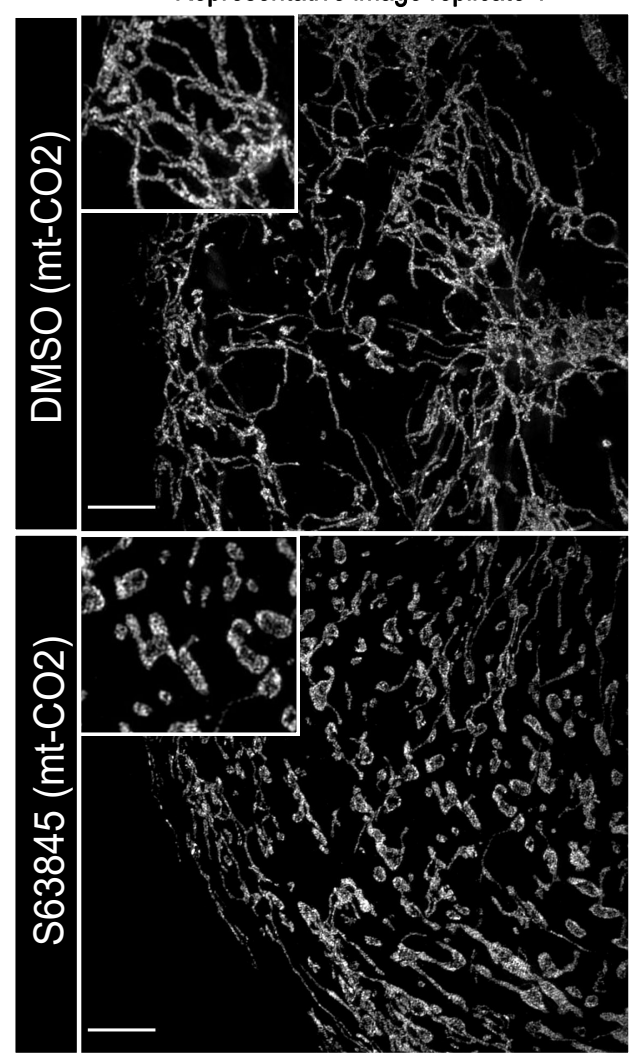

Representative image replicate 2
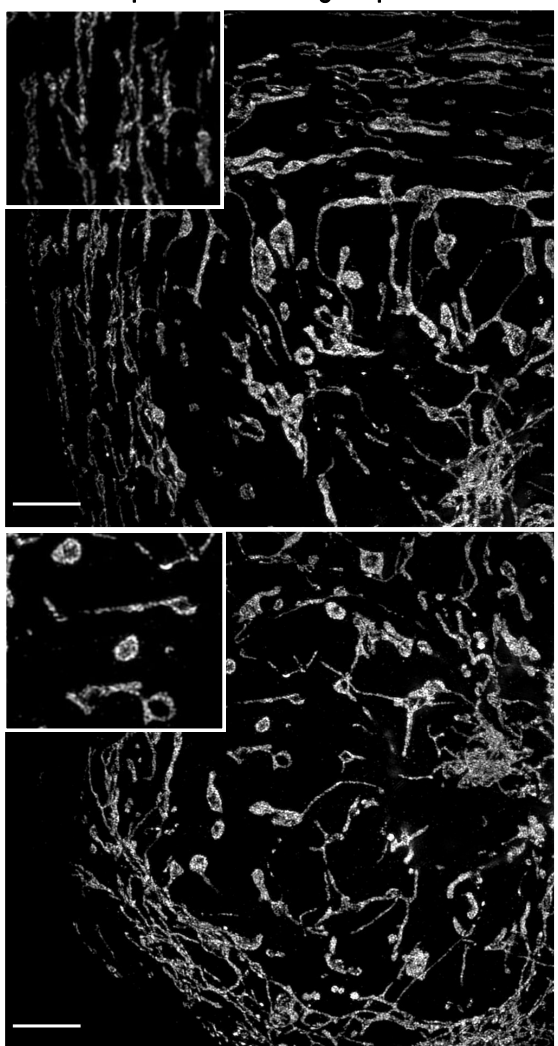

Representative image replicate 3

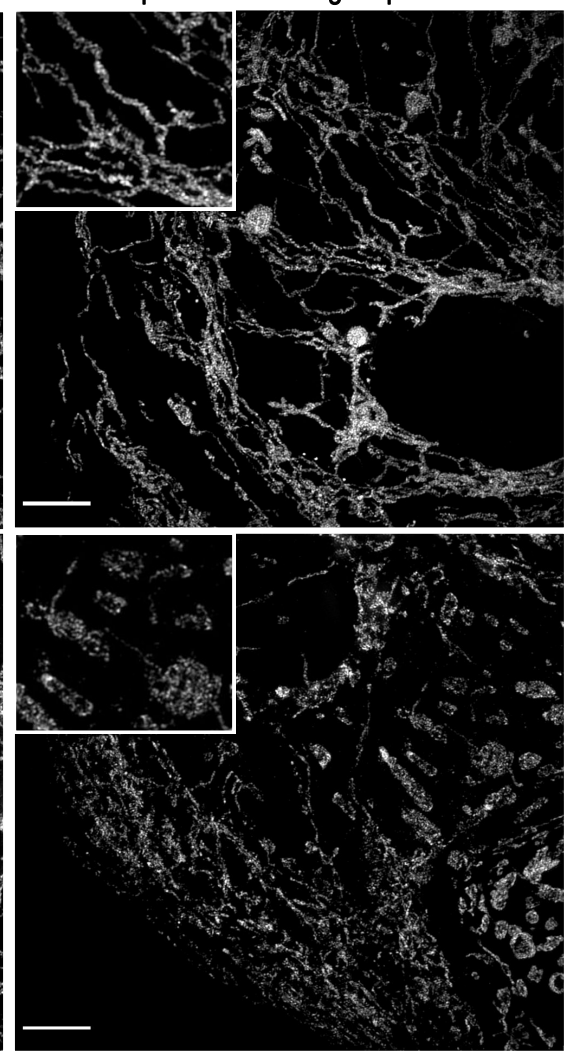




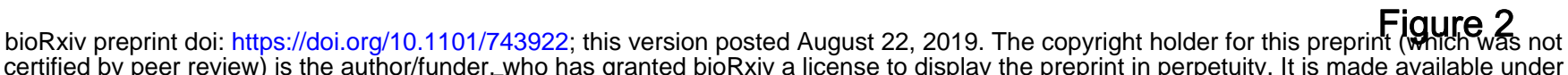
certified by peer review) is the author/funder, who has granted bioRxiv a license to display the preprint in perpetuity. It is made available under

A

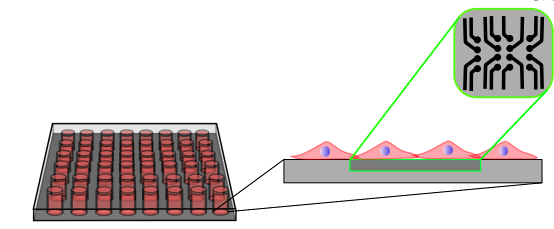

CytoView MEA plate
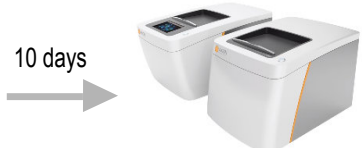

Axion Biosystem

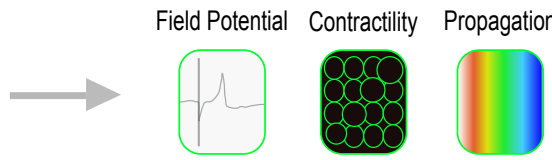

$\mathrm{D}$

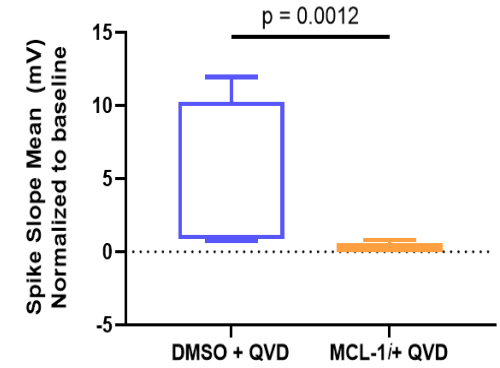

DMSO + QVD $\quad$ MCL-1i+ QVD

E

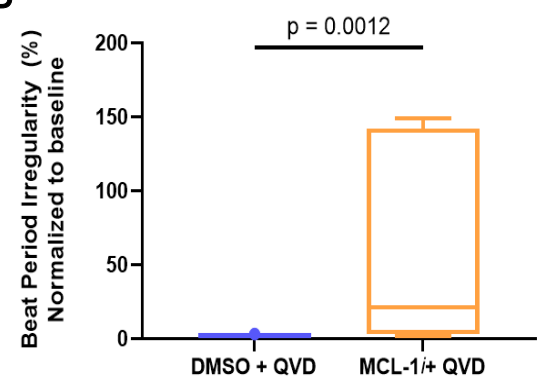

C
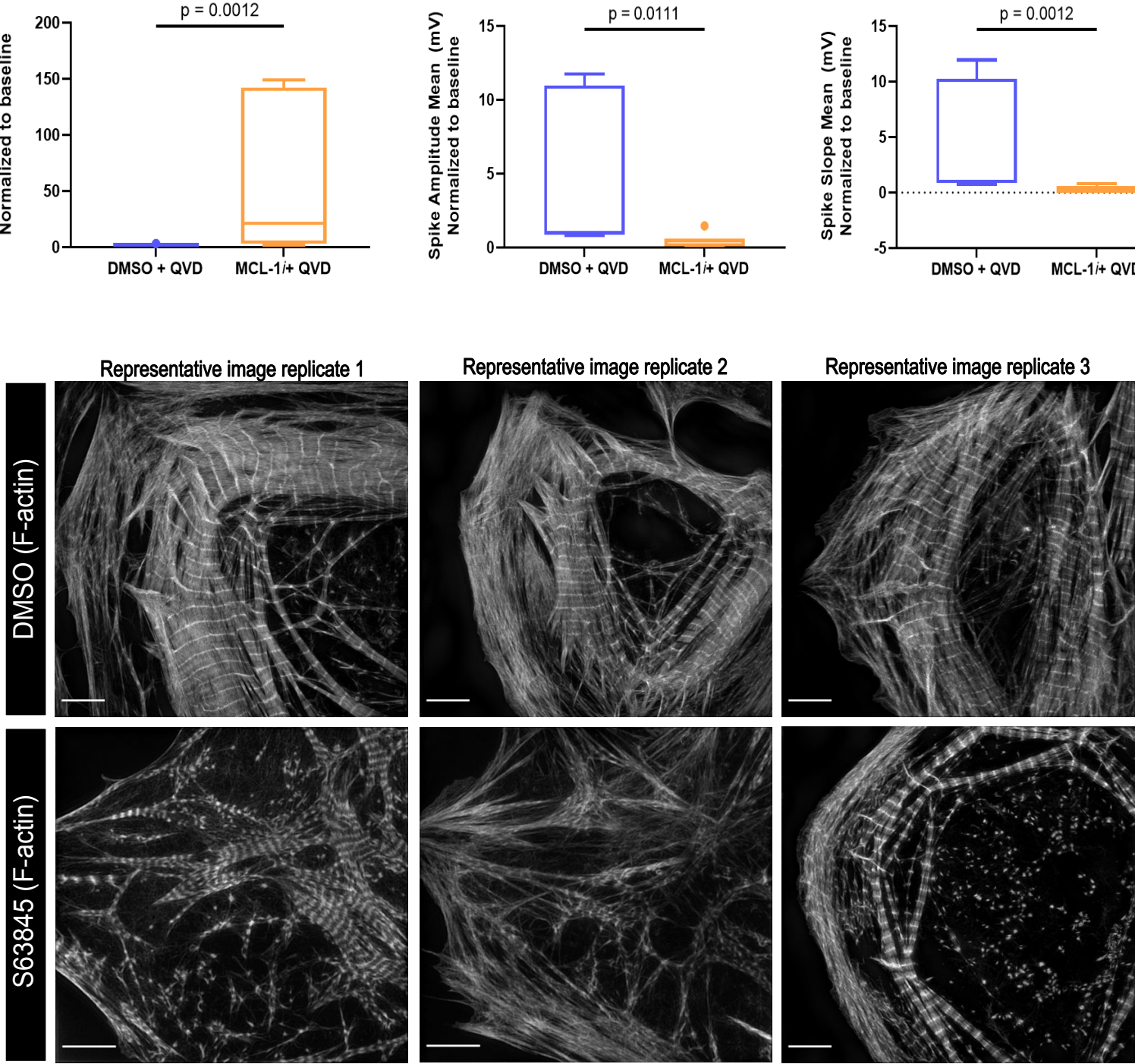

F

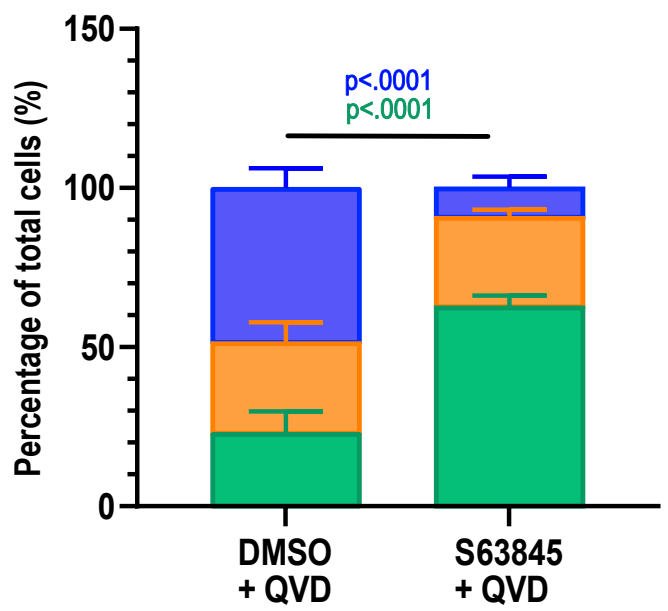

\section{Organized}

Mildly disorganized

Severely disorganized 
bioRxiv preprint doi: https://doi.org/10.1101/743922; this version posted August 22, 2019. The copyright holder for this preprinF(iglibrev33 not certified by peer review) is the author/funder, who has granted bioRxiv a license to display the preprint in perpetuity. It is made available under aCC-BY-NC-ND 4.0 International license.

A

DMSO $\mathbf{S 6 3 8 4 5}$

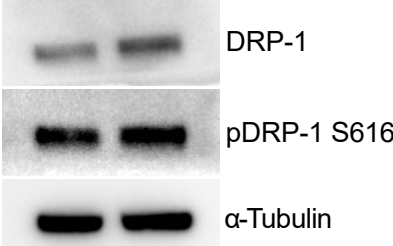

C

DMSO $\mathbf{S 6 3 8 4 5}$

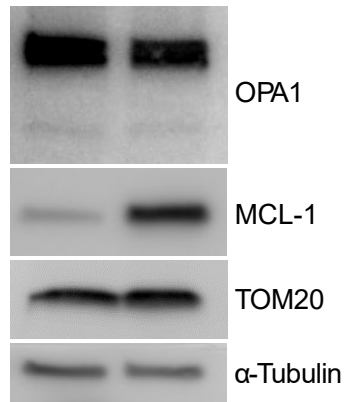

$E$

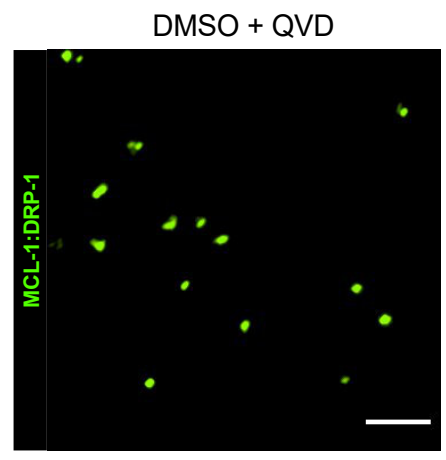

G

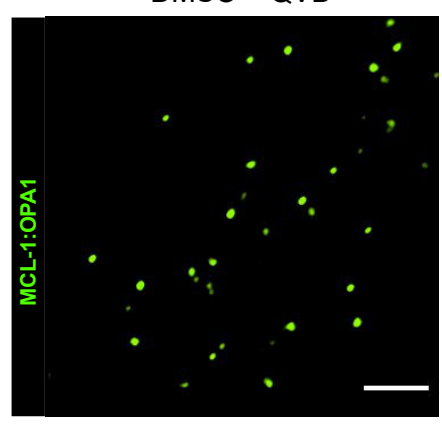

B

DRP-1

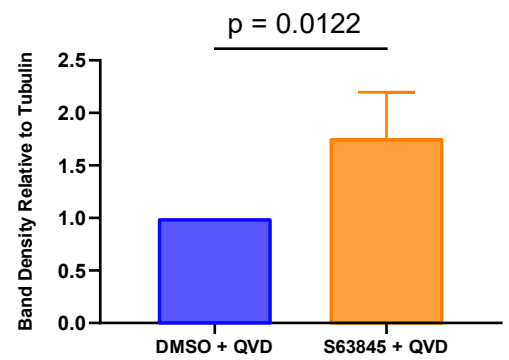

D
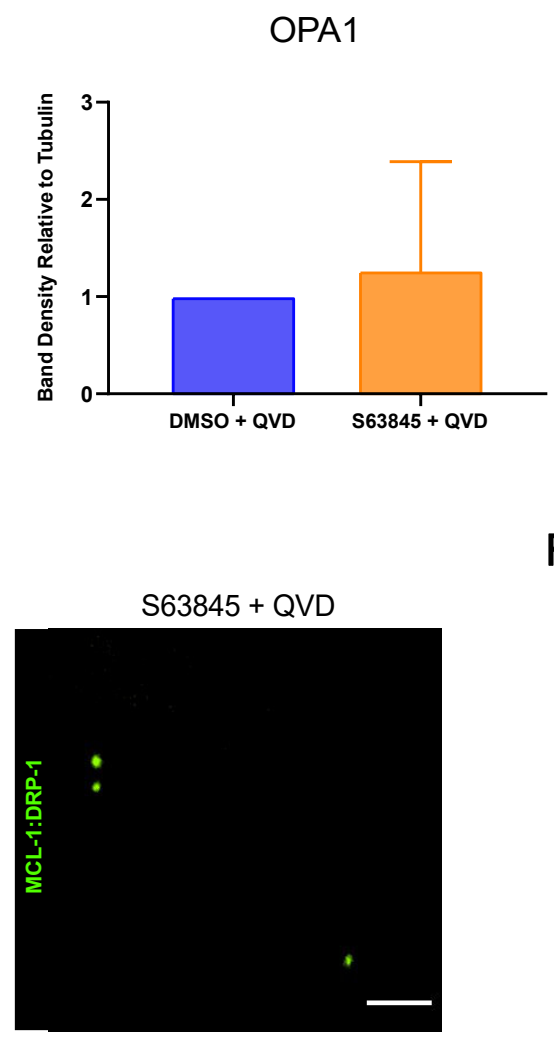

S63845 + QVD

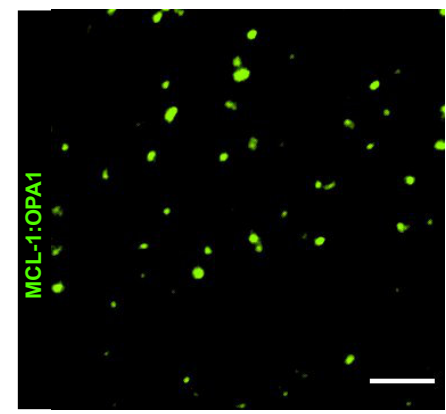

F

pDRP-1 S616

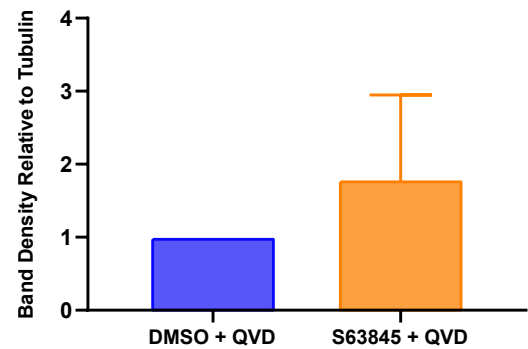

MCL-1

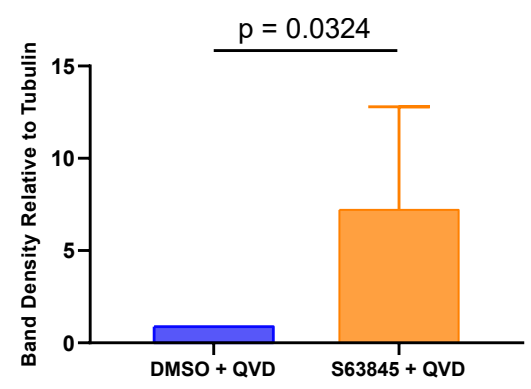

MCL-1:DRP-1

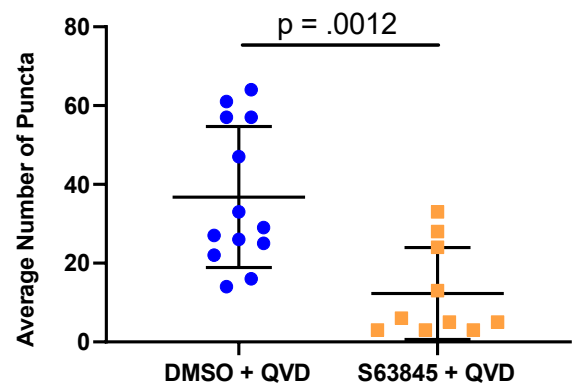

$\mathrm{H}$

MCL-1:OPA1

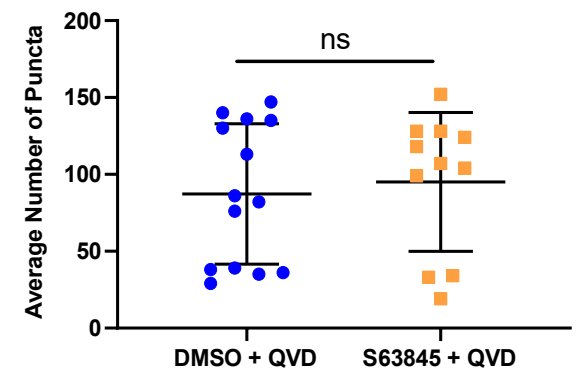


A

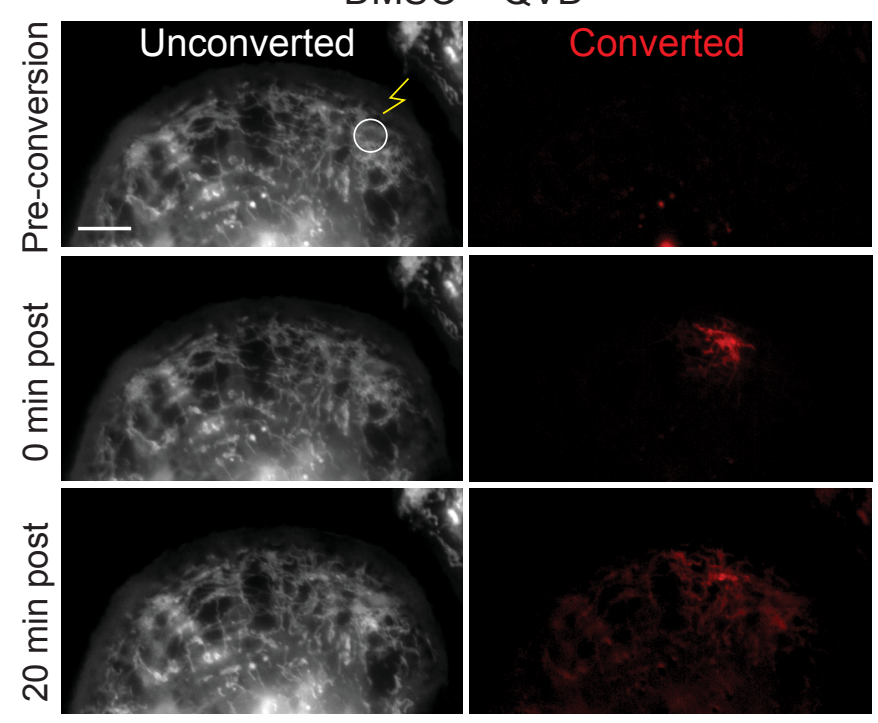

B

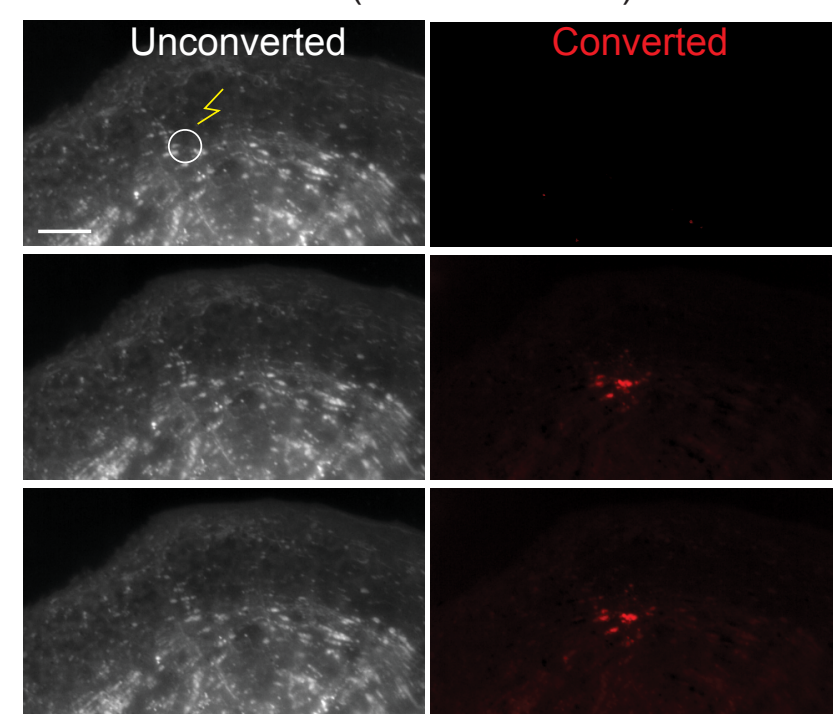

C

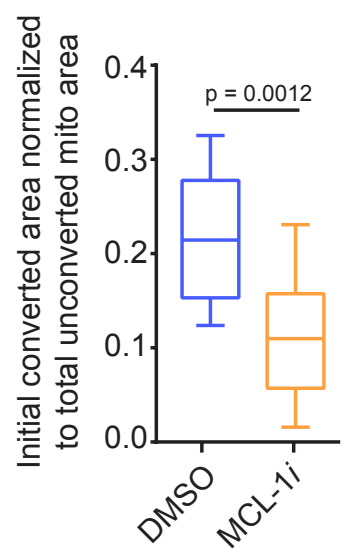

E

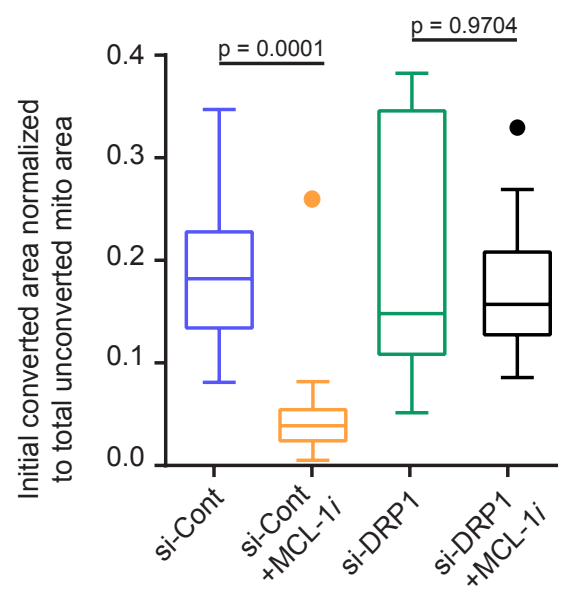

D

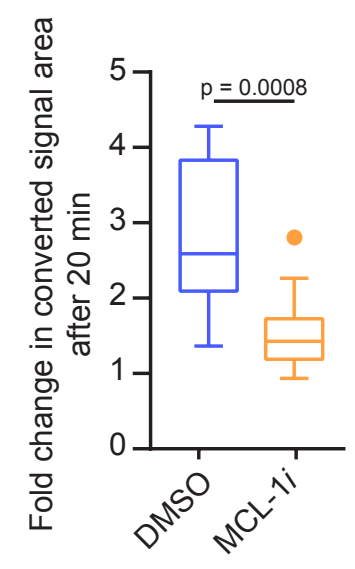

F

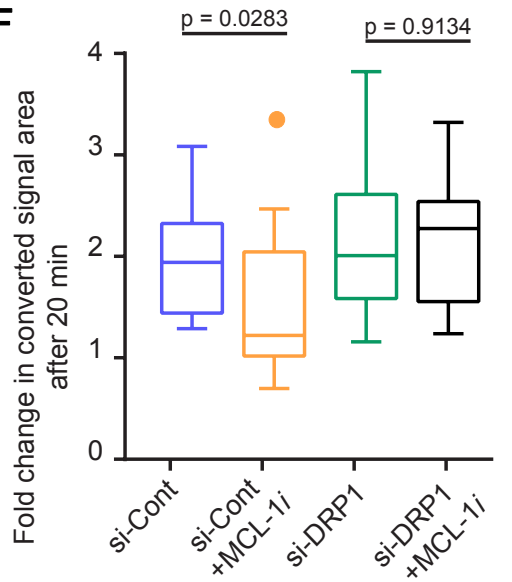


Figure 5

bioRxiv preprint doi: https://doi.org/10.1101/743922; this version posted August 22, 2019. The copyright holder for this preprint (which was not certified by peer review) is the author/funder, who has granted bioRxiv a license to display the preprint in perpetuity. It is made available under iCell hiPSC-CMs aCC-BY-NC-ND 4.0 International license.

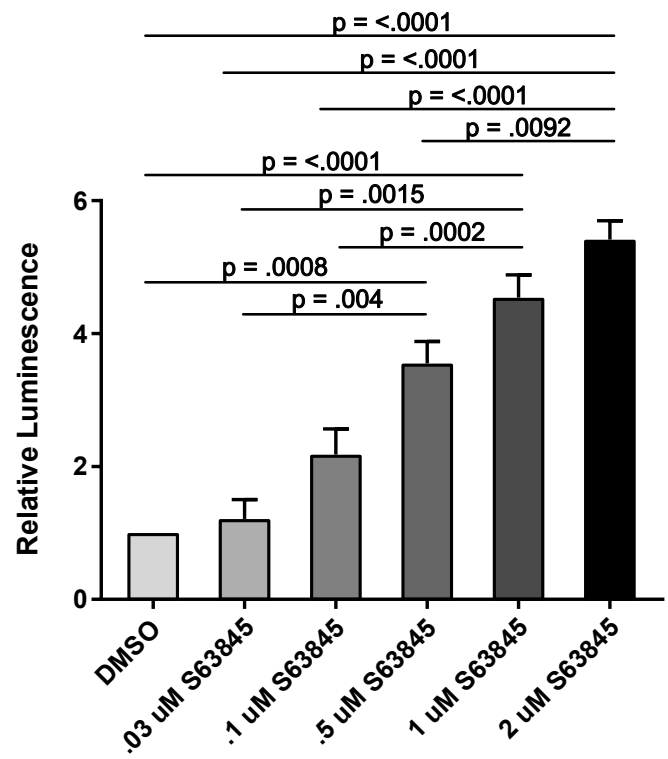

B

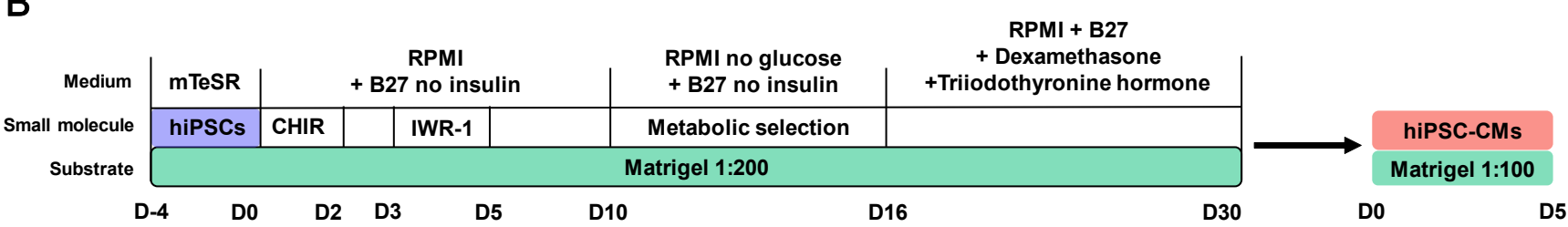

C
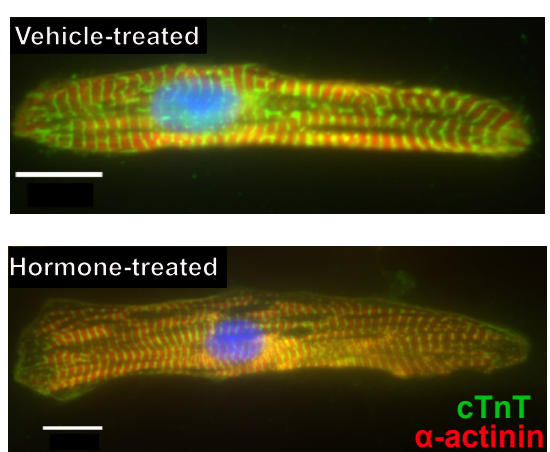

D

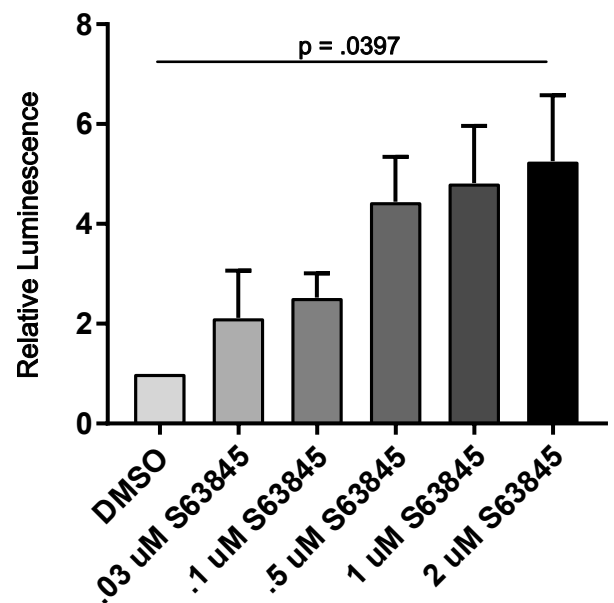

E

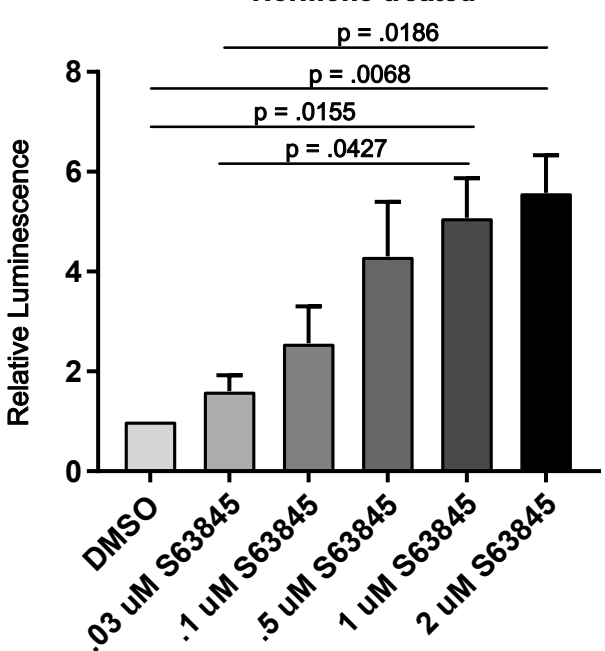


Figure 6

bjoRxiv preprint doi: https://doi.org/10.1101/743922; this version posted August 22, 2019. The copyright holder for this preprint (which was not dettified by peer review) is the author/funder, who Bas granted bioRxiv a license to display the prepsint in perpetuity. It is made available under
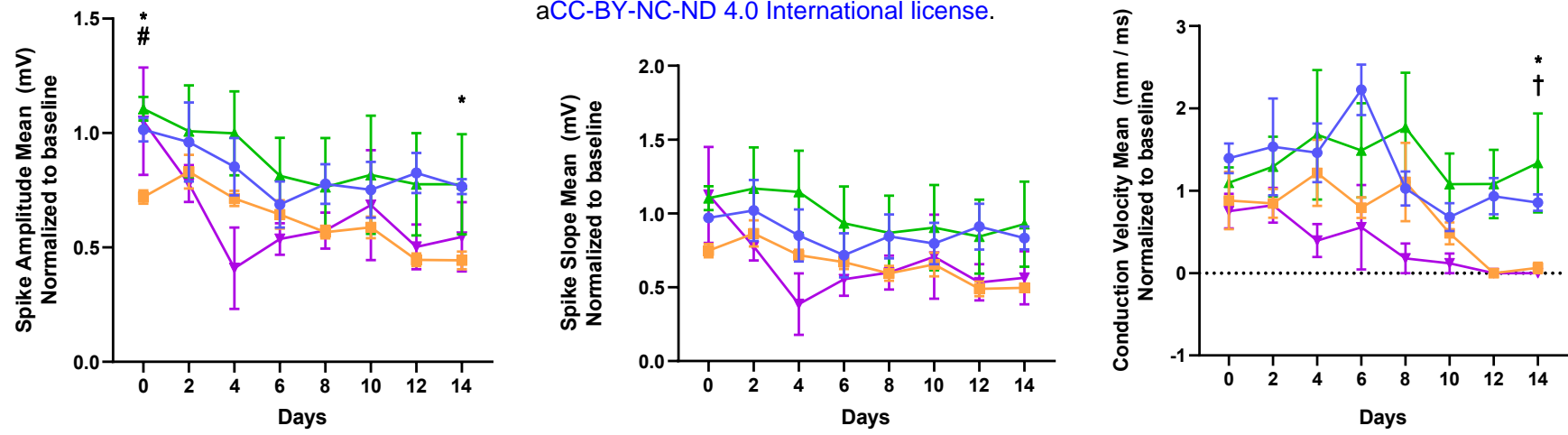

D

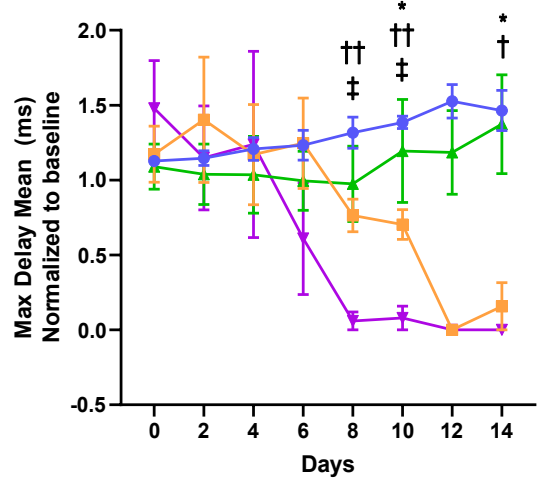

$E$

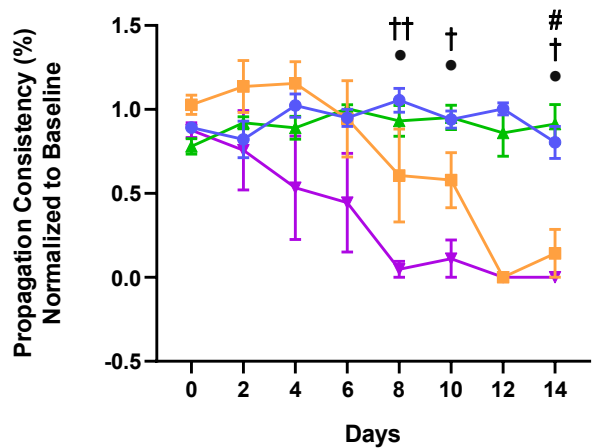

$\mathrm{H}$ $\rightarrow$ DMSO

S63845 $[100 \mathrm{nM}$

$\leftarrow$ ABT-199 [100 nM]

$\rightarrow$ Combination $[100 \mathrm{nM}]$
F

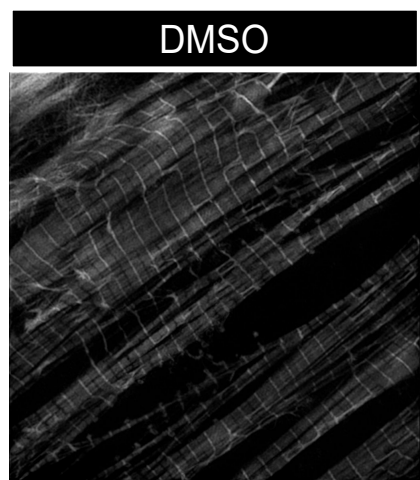

F-actin

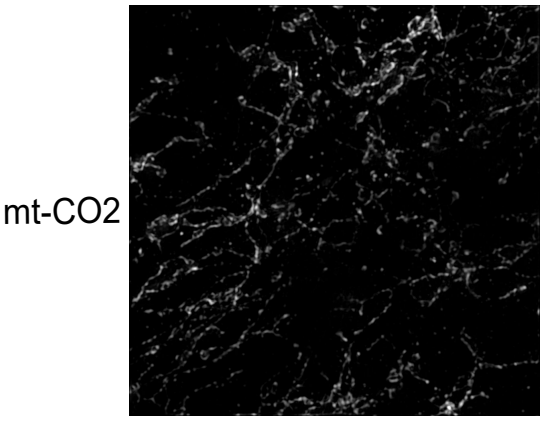

Merge

mt-CO2

F-actin
G
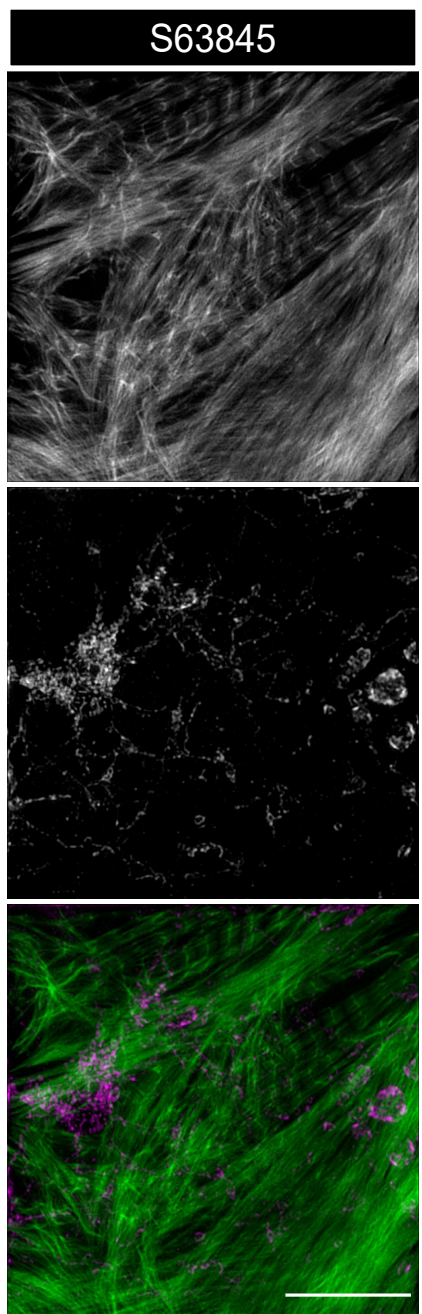
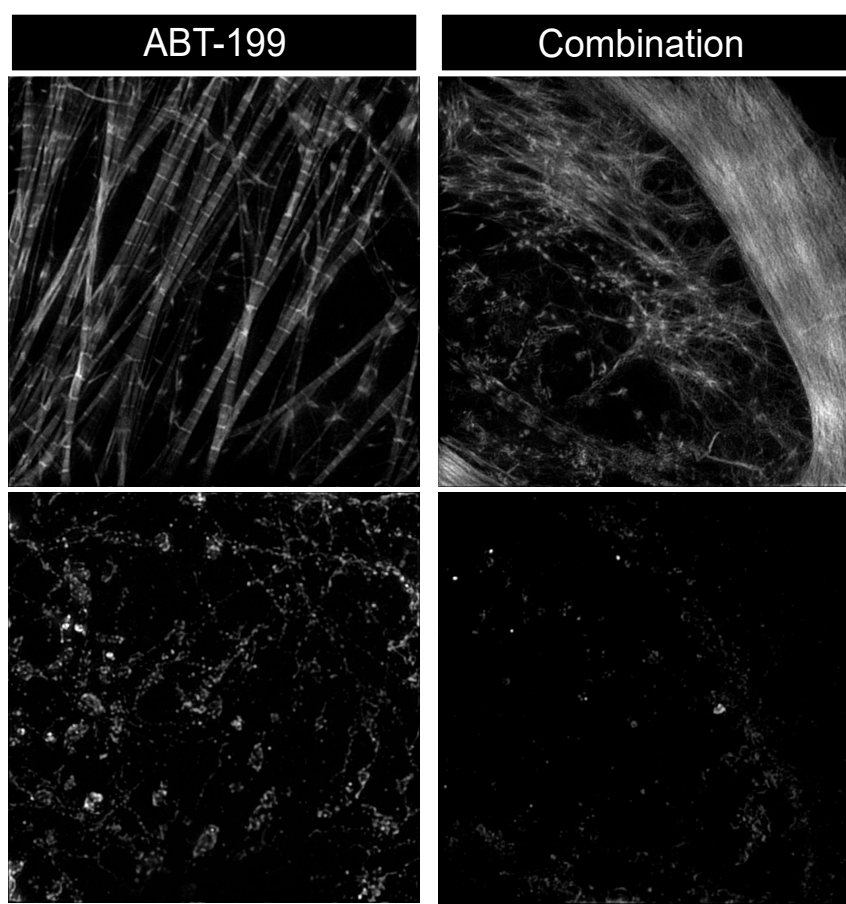
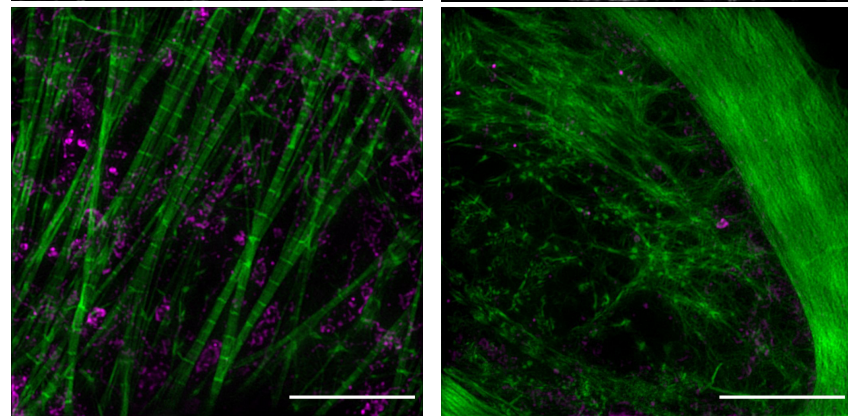